\title{
Global Collateral: \\ How Financial Innovation Drives Capital Flows and Increases Financial Instability
}

\author{
Ana Fostel* \\ John Geanakoplos ${ }^{\dagger}$ \\ Gregory Phelan $\ddagger$ \\ This version: February 4, 2017 \\ First version: July 2015
}

\begin{abstract}
We show that cross-border financial flows arise when countries differ in their abilities to use assets as collateral. Financial integration is a way of sharing scarce collateral. The ability of one country to leverage and tranche assets provides attractive financial contracts to investors in the other country, and general equilibrium effects on prices create opportunities for investors in the financially advanced country to invest abroad. Foreign demand for collateral and for collateral-backed financial promises increases the collateral value of domestic assets, and cheap foreign assets provide attractive returns to investors who do not demand collateral to issue promises. Gross global flows respond dynamically to fundamentals, exporting and amplifying financial volatility.
\end{abstract}

Keywords: Collateral, financial innovation, asset prices, capital flows, securitized markets, asset-backed securities, global imbalances.

JEL classification: D52, D53, E32, E44, F34, F36, G01, G11, G12.

*University of Virginia, Department of Economics. 237 Monroe Hall Charlottesville, VA 22904-4182, e-mail: anafostel@ gmail.com.

†Yale University, Box 208281, New Haven, CT 06520-8281 and Santa Fe Institute, e-mail: john.geanakoplos@yale.edu.

${ }_{\ddagger}^{\ddagger}$ Williams College, Department of Economics, Schapiro Hall, 24 Hopkins Hall Drive, Williamstown MA 01267, email: gp4@williams.edu, website: https://sites.google.com/site/gregoryphelan/.

We are grateful for feedback from Valentina Bruno, Emmanuel Farhi, Matteo Maggiori, Frank Warnock, and participants at the 2015 NBER IFM Summer Institute. 


\section{Introduction}

Recent decades have exhibited a proliferation of financial innovation and dramatic increases in gross international financial flows among financially developed countries. Economists have tended to focus on flows between developed and emerging economies, but gross flows among developed economies are substantial, and with important implications for intermediation costs (Bruno and Shin, 2014). These flows are by their very nature concentrated in risky assets and in "safe assets" tranched out of risky investments. Economists have begun to recognize that the rapid growth of gross global financial flows poses serious risks for macroeconomic and financial stability (Obstfeld, 2012), but the causes and consequences of these flows are not entirely understood. What mechanisms drive these financial flows, and what are the implications for stability?

We show that a collateral-based definition of financial innovation can rationalize the gross flows observed among developed countries and the recent increases in global volatility following the U.S. financial crisis. We define financial innovation as the use of new assets as collateral or new kinds of financial promises that can be issued by collateral (Fostel and Geanakoplos, 2012a). We show that cross-border differences in the ability to collateralize financial promises are enough to generate international capital flows because international financial trade is a way of sharing scarce collateral. Critically, these flows both amplify and export volatility.

Motivating evidence The following empirical observations motivate our analysis.

Observation 1: There are substantial gross financial flows between rich countries with similar levels of financial development. These gross global financial flows (countries simultaneously buying and selling foreign and domestic assets) are an order of magnitude larger than net trade in assets. In some cases these offsetting flows are heavily concentrated in financial assets and in particular in securitized mortgage securities. First, there are substantial gross flows between the U.S. and Europe. Shin (2012) documents how European banks pre-crisis greatly expanded their balance sheets, depressing spreads in the U.S. (and periphery Europe), by increasing both U.S. assets and liabilities (European banks borrowed from U.S. markets and purchased U.S. assets). Despite massive gross flows, net flows were negligible, thus absent from the current account. Similarly, Bertaut 
et al. (2012) show that during the 2000s European investors purchased U.S. asset-backed securities and similar securities. European expansion was financed by increasing liabilities, while in contrast emerging economies financed their purchases of U.S. assets using current account surpluses.

Second, there are substantial gross flows within Europe. Hale and Obstfeld (2016) show that pre-crisis, core European banks increased their balance sheets, intermediating funds from the rest of the world, to finance the net current accounts of the periphery countries-Greece, Italy, Ireland, Portugal, and Spain (“GIIPS"). As a result, core banks borrowed from abroad to invest in GIIPS. However, these flows are concentrated in just a few countries: Germany, Belgium, and France stand out among the core countries, and crucially Ireland behaved much like the core countries, intermediating funds to the other peripheral countries as well as to the core.

This evidence suggests two departures from standard models of capital flows. First, focusing on net flows alone is insufficient. While, in the early and mid 1990s net and gross flows used to move together, more recently the size and volatility of gross flows have increased while net capital flows have been more stable. As a result, the differentiation between gross inflows and outflows has become more important (Forbes and Warnock, 2012). Additionally, Acharya and Schnabl (2010) find that the geography of financial crises is determined by global banks and securitized markets, not by "global imbalances" and net flows. Second, standard models of capital flows, which focus on flows between developed and emerging economies, are not appropriate to explain the gross flows between developed economies.

Observation 2: Global flows are increasingly characterized by demand for "safe assets" and "negative-beta assets," many of which are created through financial innovations in securitized markets. Safe assets originate from the U.S., and to a lesser extent from Europe. According to the External Wealth of Nation dataset from Lane and Milesi-Ferretti (2007), in 2011, the U.S. net supply of safe assets accounted for roughly two-thirds of the global net supply of safe assets, and the Eurozone accounted for another fifth. ${ }^{1}$ Furthermore, from 1980-1990, the global net supply of safe assets was between 2 and 3\% of world GDP, and has risen to 14\% in 2011. The U.S. share was $5 \%$ in 2000 and rose to $9 \%$ in 2011 . Many have noted that the increase in safe asset supply has been

\footnotetext{
${ }^{1}$ The U.S. net supply of safe assets accounted for $9 \%$ of world GDP, and the Eurozone accounted for 3\%: total global net supply was roughly $14 \%$ of world GDP.
} 
driven primarily by financial innovations in how the U.S. securitizes assets. Finally, securitization also creates negative-beta assets because some safe assets tend to increase in value in bad states of the world. For example, long-maturity bonds increase in price in bad states because long-term interest rates decline, even as the face value of the promised payoffs remain the same.

Observation 3: Financial integration tends to increase co-movement and volatility, particularly in response to financial shocks, and particularly through banking flows and securitized markets. Many empirical papers find that financial integration increases co-movement across countries (see Imbs, 2006; Kose et al., 2008; Davis, 2014). Furthermore, financial crises are particularly likely to propagate: Santis and Gerard (1997) find that severe U.S. market declines are internationally contagious, with domestic crashes propagating through (even diversified) international portfolios; Kalemli-Ozcan et al. (2013) find that financial crises induce co-movements among financially integrated countries; Loutskina and Strahan (2015) find that the housing boom was exported via financial integration in securitized markets, thus raising the local effect of collateral shocks and increasing volatility.

Observation 4: There are substantial degrees of cross-country differences in how countries treat collateral. Many papers have empirically documented substantial degrees of cross-country heterogeneity in the ability to collateralize loans. Calza et al. (2007) show that there is significant divergence in the structure of mortgage markets across the main industrialized countries, with loanto-value ("LTV") ratios varying from between $50 \%$ in Italy and over $110 \%$ in the Netherlands. ${ }^{2}$ Kalemli-Ozcan et al. (2012) provide evidence that financial intermediary leverage differs across countries, with more leverage in the U.S. ${ }^{3}$ The evidence regarding differences in mortgage finance and intermediary leverage provide proxy evidence of cross-country differences in the depth and

\footnotetext{
${ }^{2}$ Financial innovation is often about the institutions supporting collateralization, not necessarily the collateral itself. In particular, differences in legal and regulatory frameworks, reflecting institutional differences, manifest in differing down-payment rates, repayment rates (the rate of equity release), and interest rate schedules. Warnock and Warnock $(2008,2012)$ show that among developed economies, variation in the strength of legal rights (collateral and bankruptcy laws) explain the extent of housing finance. Cerqueiro et al. (2014) document how a legal change in Sweden affected collateral values and equilibrium outcomes, providing evidence that the value of the collateral may depend not only on the value of the secured assets, but also on the legal mechanisms and institutions that define when and how a creditor can seize those assets.

${ }^{3}$ There is also heterogeneity among developing countries as well. Nguyen and Qian (2012) use data from the World Bank Enterprise Survey across 43 developing countries to show that there is substantial cross-country variation regarding how frequently collateral is used to borrow and what collateral rate is required.
} 
complexity of securitized markets. Additionally, Bertaut et al. (2012) provide consistent evidence of differential abilities to supply securitized assets.

Overview of the model and results Given this motivating evidence, we analyze how collateralbased financial innovations can produce these observed flows and increased levels of financial volatility. To that end, we consider a two-country model with incomplete markets and collateralized financial markets. Countries have different abilities to use risky assets as collateral, which gives rise to differential abilities to create risk-free and negative-beta financial securities.

We conduct our analysis using a class of models introduced by Geanakoplos (2003) called "C-models," characterized by two states of nature and a continuum of risk neutral agents with heterogenous beliefs. There are two assets, a risky and a riskless asset, that pay dividends in units of the only consumption good. The central element of our analysis is repayment enforceability problems: we suppose that agents must post collateral in order to issue financial promises.

The two countries, Home and Foreign, are identical in every way except in their ability to collateralize financial promises (assets, investors, fundamentals are all the same). The Home country has an advanced financial system that enables investors to use the risky domestic asset as collateral to issue financial promises that can be sold domestically or abroad. We consider two cases: (i) Home has a medium level of financial development that can issue non-contingent debt against the risky asset (Home can leverage the asset), (ii) Home has a high level of financial development that can issue contingent promises against the risky asset (Home can tranche the asset into negativebeta securities). In contrast, the Foreign country has a low level of financial development in which agents cannot use the risky asset as collateral at all. Our model provides precise predictions on the directions of capital flows and their effects on asset prices and financial instability.

We first conduct a static analysis to understand how financial innovation drives capital flows. Financial integration allows Foreign investors to buy Home collateral and to make financial promises unavailable before, and allows Home investors to buy cheap Foreign assets. Flows arise even though there are no interest rate differentials, nor hedging or risk-sharing motives to trade assets (agents are risk-neutral and assets have identical payoffs). Financial integration produces the following trade patterns: (i) some foreign investors purchase Home collateral in order to issue fi- 
nancial contracts; (ii) other foreign investors purchase Home collateral-backed financial promises; (iii) domestic investors without strong demands to issue financial promises purchase foreign assets with payoff properties similar to domestic assets. Additionally, financial flows tend to increase asset prices: with high levels of financial innovation, the prices of financial promises increase; Home asset prices tend to increase given their attractiveness to international agents to serve as collateral (higher collateral value); Foreign asset prices increase by virtue of being priced relative to a higher-valued alternative, the difference coming from the Home asset's role as collateral.

We then consider a dynamic setting to study the effects of financial integration on asset price volatility. Because global flows respond to changes in fundamentals, prices and leverage change dynamically. When Home can leverage its risky asset whereas Foreign cannot, we find that Foreign almost totally imports the Home "Leverage Cycle," while Home remains volatile itself. Asset markets in Foreign become much more volatile due to fluctuations in the attractiveness of alternative assets (leveraged Home assets). In other words, even assets which cannot be used as collateral behave similarly to collateralizable assets because they are priced relative to each other. When Home can tranche its risky asset to create negative-beta securities while Foreign cannot, Foreign demand for collateral-backed financial promises increases the collateral value of Home assets, amplifying pricing fluctuations driven by financial innovations. In this case asset prices in both countries become more volatile as a result of financial integration; financial flows amplify volatility. ${ }^{4}$

Our mechanism, that financial flows arise as a way to share collateral and contingent financial contracts, has several attractive features and important implications. First, trades driven by global demands to share collateral lead to gross international flows even among countries that are otherwise identical. We propose that differences in financial innovation between the U.S. and Europe contributed to the expansion of European banks' balance sheets. In particular, the ability of the U.S. financial system to leverage and tranche U.S. assets (especially mortgages) created securities in demand by European banks. ${ }^{5}$ Our story provides an attractive hypothesis to explain some of

\footnotetext{
${ }^{4}$ This is a complementary result to Fostel and Geanakoplos (2008), which shows that when the same marginal buyer uses leverage to buy two independent assets, the condition of one market spills over to the other.

${ }^{5}$ Shin argues that the regulatory environment in Europe and the advent of the Euro enabled banks to easily expand their balance sheets. We argue that the question remains: why did European banks expand by intermediating U.S. assets and liabilities as much as they did?
} 
the differences between Ireland, Germany, and the rest of Europe. Given our definition of financial innovation, the ability of a country to use assets as collateral is the feature that differentiates countries that are otherwise similarly financially developed.If collateral-based financial innovations drive gross flows, then a logical conjecture is that the wave of securitization beginning in the late 1990s could possibly explain the recent divergence between gross and net global flows.

Second, our model produces financial flows driven by demands for safe and negative-beta assets as well as in underlying risky assets. Bertaut et al. (2012) find that U.S. and European banks had similar demands for asset-backed securities, but international trade in these assets arose because of differential abilities to supply securitized assets (the U.S. was responsible for $80 \%$ of global issuance, while Europe issued only 15\%). They argue, "Because Europe was financing what were, at least ex post, risky investments in the United States through, in part, issuance of safe bank deposits and sovereign debt, it was acting as a hedge fund in the global securities market, a role previously accorded mainly to the United States." Our model produces financial flows that accord exactly with these patterns.

Third, our story has important implications for asset prices, global financial stability, and crisis transmission. Financial integration tends to increase asset prices, export volatility across borders, and amplify global volatility. ${ }^{6}$ While Shin (2012) emphasizes how expanded intermediation by European banks depresses credit spreads in the U.S., we document how global banking flows and financial linkages of the type seen between the U.S. and Europe can create serious spillovers, exporting U.S. volatility to European markets and greatly increasing the fragility of the global banking system.

Related Literature Our paper follows the model of collateral equilibrium developed in Geanakoplos (1997, 2003), Fostel and Geanakoplos (2008, 2012a,b, 2015, 2016), Geanakoplos and Zame (2014), Phelan (2015), and Gong and Phelan (2016a,b). Our paper adds to this work by studying the effect of collateral and financial innovation on global flows and international asset prices.

Our paper is related to a large literature on how differences in financial systems drive capital flows. This "global imbalances" literature has tended to focus on how net capital flows arise

\footnotetext{
${ }^{6}$ Bekaert and Harvey (2000) provide empirical evidence that financial integration increases domestic asset prices.
} 
between developed and developing countries. The literature has broadly considered differences in (i) state-completeness, (ii) the ability to supply financial assets, (iii) sharing idiosyncratic risk, and (iv) funding costs. In this literature, financial flows are driven primarily by interest rate (or investment return) differentials that manifest in different savings across countries. Financial integration leads to a convergence in savings levels and interest rates, and current account deficits can be financed indefinitely because the financially "deep" country earns intermediation rents.

Willen (2004) shows that market incompleteness across countries causes trade imbalances because superior risk-sharing in one country leads to a lower precautionary demand for saving. Caballero et al. (2008) emphasize the role of heterogeneous domestic financial systems in explaining global imbalances in which financial imperfections are captured by a country's ability to supply assets in a deterministic model. Their paper assumes that "Home" can supply more financial assets from real assets, which affects autarkic savings and interest rates, and the model can explain capital flows, current account deficits, and low interest rates. Mendoza et al. (2009) and Angeletos and Panousi (2011) have emphasized how net capital flows arise when the developed country can better insure idiosyncratic risk. Poor risk sharing increases buffer-stock savings and decreases autarkic interest rates. Within this literature, Phelan and Toda (2016) study how the risk-sharing qualities of securitized markets affect international capital flows, growth, and welfare, showing that capital flows from the high- to low-margin country. Maggiori (2013) provides a model in which Home financiers can take on greater financial risk as a result of funding advantages. This leads Home to run persistent current account deficits financed by the risk-premium earned by its financial sector, which can better absorb aggregate shocks.

While these interest rate and risk-sharing mechanisms are clearly important for understanding global flows and imbalances, we instead emphasize the role of collateral to facilitate gross flows, especially among developed countries. In our model, agents are risk-neutral, assets are identical, and interest rates do not change with financial integration (they are always zero). Flows are not driven by different savings demand. In our model all agents have the same savings demand (there is no precautionary motive), but agents have different portfolio demands. Instead, leverage and tranching create contingent securities from underlying collateral, and international trade allows 
investors to buy securities that are not available domestically. In our model, flows emerge because agents trade in underlying assets and not simply in a risk-free bond.

Finally, our focus on how financial integration leads to propagation and comovement is related to theoretical work by Mendoza and Quadrini (2010), Devereux and Yetman (2010), and Ueda (2012). These papers present models, with financial intermediaries or with leverage constraints, in which financial integration affects spillovers, propagation through interdependent portfolios, and business-cycle synchronization.

The rest of the paper is organized as follows. Section 2 presents the basic general equilibrium model with collateral. Section 3 studies the effects of financial integration on asset prices in a static model in which countries have different levels of financial innovation. Section 4 uses a three-period model to consider the dynamic consequences of financial innovation and capital flows on asset price volatility. Section 5 concludes.

\section{General Equilibrium Model with Collateral}

This section presents the $C$-model following Geanakoplos (2003). ${ }^{7}$

\section{Time and Assets}

The model is a two-period general equilibrium model, with time $t=0,1$. Uncertainty is represented by a tree $S=\{0, U, D\}$ with a root $s=0$ at time 0 and two states of nature $s=U, D$ at time 1 .

There are two assets in the economy which produce dividends of the consumption good $c$ at time 1. The riskless asset $X$ produces $d_{U}^{X}=d_{D}^{X}=d^{X}$ unit of the consumption good in each state, and the risky asset $Y$ produces $d_{U}^{Y}$ unit in state $U$ and $0<d_{D}^{Y}<d_{U}^{Y}$ unit of the consumption good in state $D$. Figure 1 shows asset payoffs.

\footnotetext{
${ }^{7}$ None of the results depend on risk neutrality or heterogeneous priors. By assuming common probabilities and strictly concave utilities, and adding large endowments in state $D$ vs state $U$ for agents with high $i$ and low endowments in state $D$ vs state $U$ for agents with low $i$, we could reproduce the distribution of marginal utilities we get from differences in prior probabilities. We have chosen to replace the usual marginal analysis of consumers who have interior consumption with a continuum of agents and a marginal buyer. Our view is that the slightly unconventional modeling is a small price to pay for the simple tractability of the analysis.
} 


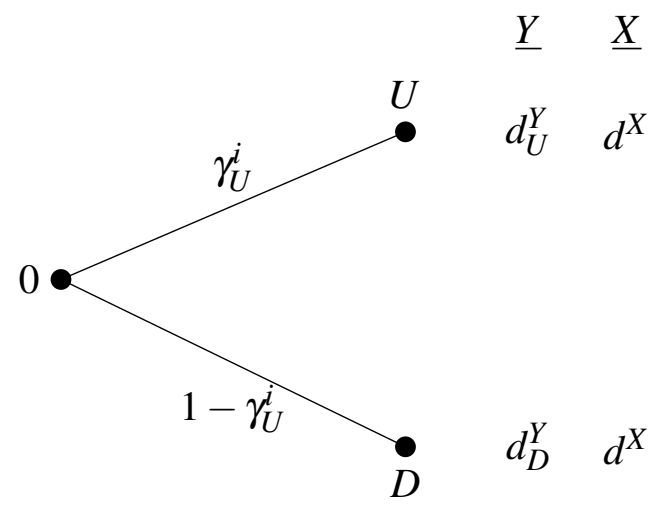

Figure 1: Asset Payoffs.

We can always normalize one price in each state, so we take the price of $X$ in state 0 and the price of consumption in each state $U, D$ to be one. Thus $X$ is both riskless and the numeraire (it is analogous to a durable consumption good like gold, or to money, in our one commodity model). The price of the risky asset $Y$ at time 0 is denoted by $p$.

\section{Agents}

Agents are uniformly distributed in the continuum $(0,1)$ described by Lebesgue measure. Each investor $i \in(0,1)$ is risk-neutral and characterized by a linear utility for consumption of the single consumption good $c$ at time 1 , with subjective probabilities $\left(\gamma_{U}^{i}, \gamma_{D}^{i}\right)=(\gamma(i), 1-\gamma(i))$. The vonNeumann-Morgenstern expected utility to agent $i$ is

$$
U^{i}\left(c_{U}, c_{D}\right)=\gamma_{U}^{i} c_{U}+\gamma_{D}^{i} c_{D}
$$

We suppose that $\gamma(i)$ is strictly increasing and continuous in $i$. Since only the output of $Y$ depends on the state and $0<d_{D}^{Y}<d_{U}^{Y}$, higher $i$ denotes more optimism. Heterogeneity among the agents stems entirely from the dependence of $\gamma(i)$ on $i$.

Each investor $i \in(0,1)$ has endowments $e^{X}$ and $e^{Y}$ of assets $X$ and $Y$ respectively at time 0 and nothing else. Hence, consumption at time 1 is entirely derived from asset dividends. 


\section{Financial Contracts and Collateral}

The heart of our analysis involves contracts and collateral. We explicitly incorporate repayment enforceability problems. ${ }^{8}$ Agents cannot be coerced into honoring their promises except by seizing collateral agreed upon by contract in advance. Agents need to post collateral in the form of durable assets in order to issue promises.

At time 0 agents can trade financial contracts. A financial contract $j=\left(\left(j_{U}, j_{D}\right), C_{j}\right)$ consists of both a promise $\left(j_{U}, j_{D}\right)$ of repayment in terms of the consumption good at each state, and an asset $C_{j}$ acting as collateral backing it. Without loss of generality, we suppose every contract is collateralized by one unit $Y$. We denote the total set of contracts by $J$.

The lender has the right to seize as much of the collateral as will make him whole once the promise comes due, but no more. Since $C_{j}=Y$, in the two states the contract therefore delivers

$$
\left(\min \left(j_{U}, d_{U}^{Y}\right), \min \left(j_{D}, d_{D}^{Y}\right)\right)
$$

We denote the sale of promise $j$ by $\varphi_{j}>0$ and the purchase of the same contract by $\varphi_{j}<0$. The sale of a contract corresponds to borrowing the sale price, and the purchase of a promise is tantamount to lending the price in return for the promise. The sale of $\varphi_{j}>0$ units of contract type $j \in J$ requires the ownership of $\varphi_{j}$ units of $Y$, whereas the purchase of the same number of contracts does not require any ownership of $Y$.

Each contract $j \in J$ trades at price $\pi^{j}$. An investor can borrow $\pi^{j}$ today by selling contract $j$ in exchange for a promise of $\left(j_{U}, j_{D}\right)$ tomorrow, provided she owns $Y$.

\section{Budget Set}

Given asset and contract prices at time $0,\left(p,\left(\pi^{j}\right)_{j \in J}\right)$, each agent $i \in I$ choses asset holdings $x$ of $X$ and $y$ of $Y$, contract trades $\varphi_{j}$ in state 0 , and consumption in final states $c_{U}, c_{D}$, in order to maximize utility (1) subject to the budget set defined by

\footnotetext{
${ }^{8} \mathrm{We}$ exclude cash flow problems. The value of the collateral in each future state does not depend on the size of the promise, or on what other choices the seller makes, or on who owns the asset at the very end. This eliminates any issues associated with hidden effort or unobservability. For an extensive analysis on the of the implications on asset prices, leverage and production arising from the distinction see Fostel and Geanakoplos $(2016,2015)$.
} 


$$
\begin{gathered}
B^{i}(p, \pi)=\left\{\left(x, y, \varphi, c_{U}, c_{D}\right) \in R_{+} \times R_{+} \times R^{J} \times R_{+} \times R_{+}:\right. \\
\left(x-e^{X}\right)+p\left(y-e^{Y}\right) \leq \sum_{j \in J} \varphi_{j} \pi^{j} \\
\sum_{j \in J} \max \left(0, \varphi_{j}\right) \leq y \\
\left.c_{s}=x d^{X}+y d_{s}^{Y}-\sum_{j \in J} \varphi_{j} \min \left(j_{s}^{j}, d_{s}^{Y}\right), s=U, D\right\}
\end{gathered}
$$

At time 0, expenditures on the assets purchased (or sold) cannot exceed the value borrowed selling contracts using the assets as collateral. The assets put up as collateral must be owned. Consumption in the final states equals dividends of the assets held minus debt repayment.

\section{Collateral Equilibrium}

A Collateral Equilibrium in this economy is a price of asset $Y$, contract prices, asset purchases, contract trades and consumption decisions by all the agents $\left((p, \pi),\left(x^{i}, y^{i}, \varphi^{i}, c_{U}^{i}, c_{D}^{i}\right)_{i \in I}\right) \in\left(R_{+} \times\right.$ $\left.R_{+}^{J}\right) \times\left(R_{+} \times R_{+} \times R^{J} \times R_{+} \times R_{+}\right)^{H}$, such that

1. $\int_{0}^{1} x^{i} d i=e^{X}$

2. $\int_{0}^{1} y^{i} d i=e^{Y}$

3. $\int_{0}^{1} \varphi_{j}^{i} d i=0 \forall j \in J$

4. $\left(x^{i}, y^{i}, \varphi^{i}, c_{U}^{i}, c_{D}^{i}\right) \in B^{i}(p, \pi), \forall i$

5. $\left(x, y, \varphi, c_{U}, c_{D}\right) \in B^{i}(p, \pi) \Rightarrow U^{i}(x) \leq U^{i}\left(x^{i}\right), \forall i$

In equilibrium, all markets clear and agents optimize their utility in their budget sets. Geanakoplos and Zame (2014) show that, given our assumptions, equilibrium in this model always exists.

\section{Collateral and Financial Innovation}

A vitally important source of financial innovation involves the possibility of using assets as collateral to back promises. We define financial innovation as the use of new kinds of collateral, or new kinds of promises that can be backed by the same collateral. Financial innovation in our model then, is described by a different set $J$. In Sections 3 and 4 we will analyze different economies obtained by varying the set $J$. 
These simplifications are to reflect in the simplest setting key differences in available financial instruments. Financial systems differ in a myriad of both subtle and complex ways-for example, the level of insurance and risk sharing-but the salient features that we are focusing on are the ability to leverage, securitize and tranche assets, which is reflected in the financial structures we assume. We model investors as borrowing directly against assets and issuing tranches against the assets, but this could capture the role of financial intermediary in producing the financial assets that correspond to these cash flows.

\section{A Static Model of Global Flows}

We now consider a model with two countries, Home and Foreign (denoted by $*$ ), each defined as the economy in Section 2. Both countries are identical in every way except for the feasible contracts available in each country, $J$ and $J^{*}$. In both countries there is a risky asset $Y$ and $Y^{*}$ and a risk-free asset $X$ and $X^{*}$, with identical state-payoffs as defined in Figure 1. In each country there is a unit continuum of identical investors. Risky assets prices in each country are denoted by $p$ and $p^{*}$.

Home has a more advanced financial system than Foreign. To simplify, we assume that Foreign agents are not able to use assets as collateral to issue financial promises, that is $J^{*}=\emptyset$. In contrast, at Home agents can use the risky asset as collateral $(J \neq \emptyset$ will vary to reflect financial innovation at Home). We consider two different forms of financial innovations at Home, leverage and tranching: with leverage agents can use the risky asset $Y$ to issue non-contingent promises (debt); with tranching agents can use the risky asset to issue contingent promises. With financial integration countries can trade assets and financial promises. ${ }^{9}$

The main insight from the static analysis is that the difference in financial systems is enough to generate international capital flows: financial trade is a way of internationally sharing scarce collateral. In the appendix we consider an extension of the model with differentiated goods to study

\footnotetext{
${ }^{9}$ In the Appendix we consider two additional variations. First, when Home can tranche assets and countries can trade tranches but not the risky assets. This is a natural case to consider because in many cases the underlying collateral cannot be traded internationally, as is the case for houses. Second, when the Foreign financial sector can leverage assets against debt and the Home financial sector can tranche assets.
} 
how financial innovation affects exchange rates. The main result is that leverage and tranching lead to an appreciation of the Home currency (see Appendix A.3).

Finally, in the remainder of the paper we will solve for equilibrium for the following set of parameters: agents' utilities and endowments in both countries are given by $\gamma(i)=1-(1-i)^{2}$,

$e^{Y}=e^{X}=1$, and asset payoffs in both countries are given by and $d^{X}=d_{U}^{Y}=1$ and $d_{D}^{Y}=.2$. However, our results are robust to the choice of parameters (we discuss parameter sensitivity and comparative statics throughout; also see Fostel and Geanakoplos, 2012a).

\subsection{Leverage and Global Flows}

The Home financial sector can issue non-contingent promises using the asset as collateral. In this case $J=J^{Y}=\{j: j=((j, j), 1)\}$. As mentioned before $J^{*}=\emptyset$. We first describe autarkic equilibria in each country and then describe the equilibrium with financial integration.

\subsubsection{Autarky: Foreign}

In autarky, Foreign agents can only trade assets $Y^{*}$ and $X^{*}$; they cannot borrow using the assets as collateral. Given the strict monotonicity and continuity of $\gamma(i)$ in $i$, linear utilities, and the connectedness of the set of agents $(0,1)$, in equilibrium at state $s=0$ there is a unique marginal buyer, $i^{Y^{*}}$, who is indifferent between holding $Y^{*}$ and $X^{*}$. Agents $i>i^{Y^{*}}$ sell their endowment of $X^{*}$ to buy $Y^{*}$. Agents $i<i^{Y^{*}}$ sell all their endowment of $Y^{*}$ to buy $X^{*}$. Equilibrium is described by a system of two equations in two unknowns: the price of the asset, $p^{*}$, and the marginal buyer, $i^{Y^{*}}$ :

$$
\begin{gathered}
1=\left(1-i^{Y^{*}}\right) \frac{\left(1+p^{*}\right)}{p^{*}} \\
p^{*}=\gamma\left(i^{Y^{*}}\right) 1+\left(1-\gamma\left(i^{Y^{*}}\right)\right) d_{D}^{Y} .
\end{gathered}
$$

Equation (2) is market clearing for the risky asset; equation (3) says that the marginal buyer is indifferent between buying the risky asset and holding cash. For the given parameters, equilibrium is given by $i^{Y^{*}}=.54$ and $p^{*}=.83$. 


\subsubsection{Autarky: Home}

Home agents can borrow by issuing non-contingent promises using the risky asset as collateral. Leverage is endogenously determined in equilibrium: although all contracts will be priced in equilibrium, the only contract actively traded is the "max min" contract $j_{*}=\min _{s=U, D}\left\{d_{s}^{Y}\right\}=d_{D}^{Y}$, ruling out default in equilibrium (Fostel and Geanakoplos, 2012b). Furthermore, the risk-less interest rate is equal to zero, this is, $\pi^{j_{*}}=j_{*}=d_{D}^{Y}$.

In equilibrium there is a marginal buyer, $i^{Y}$, who is indifferent between holding $X$ and buying $Y$ with leverage. All agents $i>i^{Y}$ buy $Y$ with leverage: they sell their endowment of $X$ and borrow $d_{D}^{Y}$ using $Y$ as collateral. Notice that when agents buy the asset $Y$ with leverage, they are effectively buying the Arrow $U$ security and they end up consuming only at state $U$. Agents $i<i^{Y}$ sell their endowment of $Y$ and lend to the more optimistic investors, holding $X$ and risk-free financial promises. Equilibrium is described by a system of two equations in two unknowns:

$$
\begin{gathered}
1=\left(1-i^{Y}\right) \frac{(1+p)}{p-d_{D}^{Y}} \\
p=\gamma\left(i^{Y}\right) 1+\left(1-\gamma\left(i^{Y}\right)\right) d_{D}^{Y} .
\end{gathered}
$$

Equation (4) differs from equation (2) because Home optimists can borrow $d_{D}^{Y}$, implying that equilibrium requires a fewer number of optimists to buy all the asset in the economy. Hence, the marginal buyer in the Home economy will be more optimistic than the marginal buyer in the Foreign economy.

For the given parameters, equilibrium is given by $i^{Y}=.63$ and $p=.89$. Both the marginal buyer and the asset price are higher at Home than at Foreign in autarky because $Y$ has a collateral value. $^{10}$

\subsubsection{Financial Integration with Leverage}

With financial integration, Home and Foreign agents can trade assets and bonds, and any agent can use the Home asset $Y$ as collateral in order to borrow. We denote equilibrium variables after finan-

\footnotetext{
${ }^{10}$ See Geanakoplos (2003) and Fostel and Geanakoplos (2008) for an early treatment of Collateral Value.
} 
cial integration by a 'hat' $\left(^{\wedge}\right)$ to distinguish them from their autarky counterparts. In equilibrium, in each country there are two common marginal investors $\hat{i}^{Y}$ and $\hat{i}^{Y^{*}}$. The marginal investors in each country are the same because the assets are have identical payoffs and agents have the same beliefs $\gamma(i)$. Investors $i \geq \hat{i}^{Y}$ in both countries buy $Y$ on margin (hence holding the Arrow $U$ security); investors $i \in\left(\hat{i}^{*}, \hat{i}^{Y}\right)$ in both countries buy $Y^{*}$ with cash; and the remaining investors hold $X$ and $X^{*}$, and risk-free debt. Figure 2 shows equilibrium.

Financial integration affects equilibrium even though assets in both countries have identical payoffs and agents are identical. This is because $Y$ can serve as collateral. Investors that buy $Y$ are able to borrow against their asset purchases and leverage their positions. Optimistic Foreign investors believe that $U$ is very likely: they prefer to buy $Y$ with leverage than $Y^{*}$. At the same time, moderate Home investors are unwilling to buy $Y$ with leverage (because the price is high) and prefer to buy $Y^{*}$ at a lower price without leverage. Thus, cheap Foreign assets are attractive to Home investors who are otherwise priced out of the Home market by optimistic, leveraged investors.

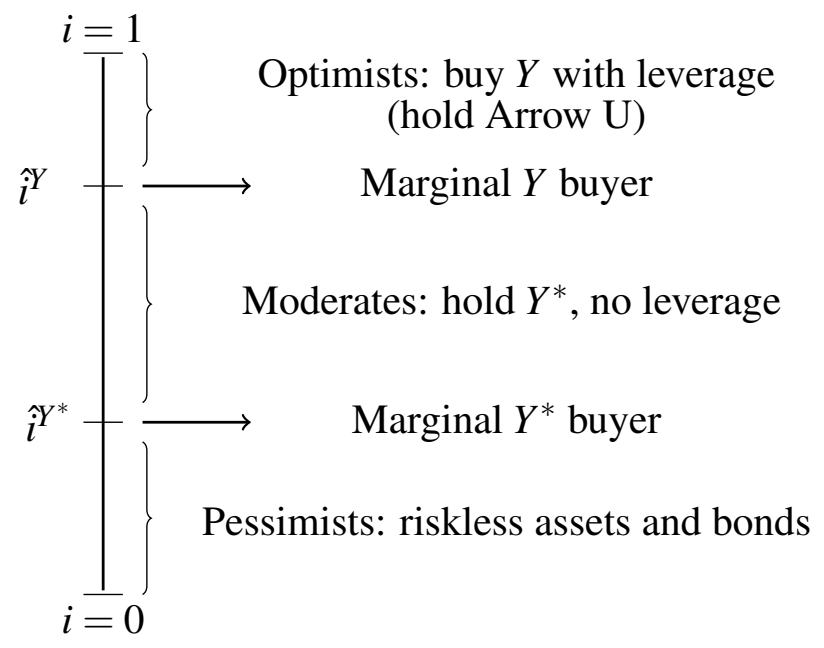

Figure 2: Equilibrium Regime with Leverage and Financial Integration.

Equilibrium is described by a system of four equations in four unknowns: the prices of the assets, $\hat{p}^{*}$ and $\hat{p}$, and the marginal buyers, $\hat{i}^{Y^{*}}$ and $\hat{i}^{Y}$. The marginal buyer $\hat{i}^{Y}$ is indifferent between 
the leveraged return on $Y$ and the un-leveraged return $Y^{*}$ :

$$
\frac{\gamma\left(\hat{i}^{Y}\right)\left(1-d_{D}^{Y}\right)}{\hat{p}-d_{D}^{Y}}=\frac{\gamma\left(\hat{i}^{Y}\right)+\left(1-\gamma\left(\hat{i}^{Y}\right)\right) d_{D}^{Y}}{\hat{p}^{*}} .
$$

The marginal buyer $\hat{i}^{Y^{*}}$ is indifferent between the un-leveraged return on $Y^{*}$ and holding the riskfree asset (and bond):

$$
\hat{p}^{*}=\gamma\left(\hat{i}^{*}\right) 1+\left(1-\gamma\left(\hat{i}^{Y^{*}}\right)\right) d_{D}^{Y}
$$

Market clearing conditions for $Y$ and $Y^{*}$ are given by

$$
\begin{gathered}
1=\left(1-\hat{i}^{Y}\right) \frac{\left(2+\hat{p}+\hat{p}^{*}\right)}{\hat{p}-d_{D}^{Y},} \\
1=\left(\hat{i}^{Y}-\hat{i}^{Y^{*}}\right) \frac{\left(2+\hat{p}+\hat{p}^{*}\right)}{\hat{p}^{*}} .
\end{gathered}
$$

Compared to (4), the market clearing condition (8) includes wealth from both countries. ${ }^{11}$ Therefore, the marginal buyer $\hat{i}^{Y}$ increases as a result of trade. Compared to equation (5), in equation (6) the alternative return to leveraging $Y$ is not a risk-free return but rather the un-leveraged return on $Y^{*}$. For investor $\hat{i}^{Y}$ the un-leveraged return on $Y^{*}$ is greater than 1 -it is a more attractive alternative than cash. This effect will tend to increase the return to leveraging $Y$, which will decrease the price $\hat{p}$ even though the marginal investor will increase.

Table 1 show the equilibrium prices for the same parameter values. Figure 3 illustrates the effects of financial integration on marginal investors and financial flows.

\footnotetext{
${ }^{11}$ To calculate the market clearing condition for $Y$, remember that investors will buy $\frac{1}{\hat{p}-d_{D}^{Y}}$ units of the asset for every unit of wealth. Investors in $\mathrm{H}$ are endowed with $X$ and $Y$ and thus have wealth $1+\hat{p}$; similarly, investors in $\mathrm{F}$ have wealth $1+\hat{p}^{*}$. Since all investors $i \geq \hat{i}^{Y}$ in each country buy the Home asset, the total global demand is given by

$$
\int_{\hat{i}^{Y}}^{1}\left(\frac{1+\hat{p}}{\hat{p}-d_{D}^{Y}}\right) d i+\int_{\hat{i}^{Y}}^{1}\left(\frac{1+\hat{p}^{*}}{\hat{p}-d_{D}^{Y}}\right) d i=\left(1-\hat{i}^{Y}\right)\left(\frac{2+\hat{p}+\hat{p}^{*}}{\hat{p}-d_{D}^{Y}}\right)
$$

Equating with the unit supply of $Y$ yields the market clearing condition for the Home asset. The same exercise yields the result for $Y^{*}$.
} 
Table 1: Equilibrium Prices with Leverage.

\begin{tabular}{l|c|c} 
& Autarky & Integration $\left(^{\wedge}\right)$ \\
\hline Home Asset Price: $p$ & .893 & $.886 \downarrow$ \\
Foreign Asset Price: $p^{*}$ & .834 & $.864 \uparrow$ \\
Debt Price: $\pi^{.2}$ & .2 & .2
\end{tabular}

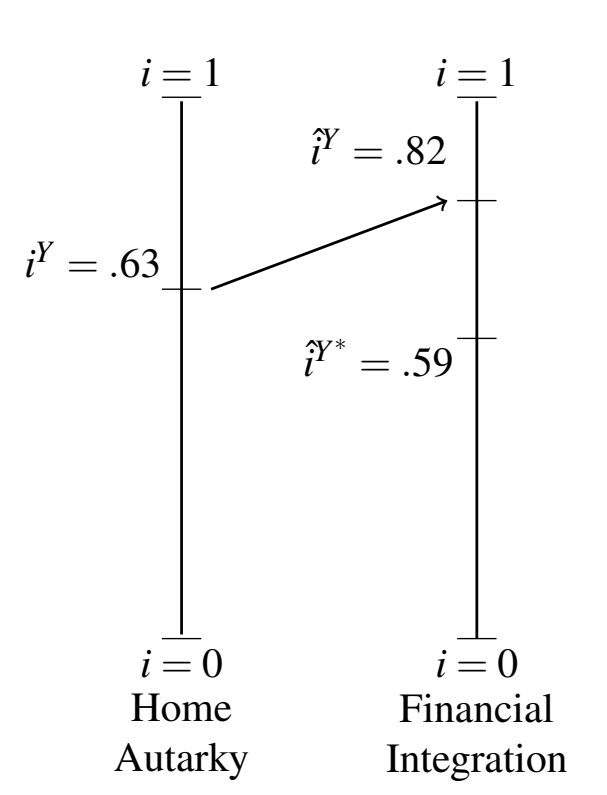

\section{Financial Flows}

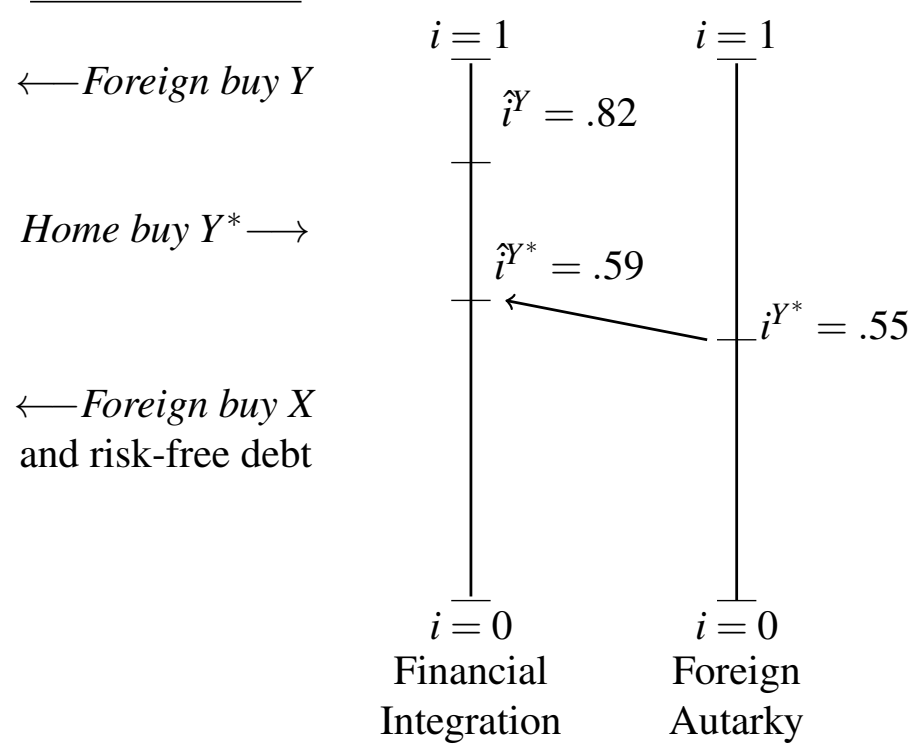

Figure 3: Equilibrium with Financial Integration and Leverage.

\subsubsection{Leverage and Global Flows}

Differences in the ability to collateralize financial promises across borders are enough to generate international capital flows. In our model, the are no interest rate differentials, nor hedging or risk-sharing motives to trade assets (agents are risk-neutral and assets have identical payoffs). International financial trade is a way of internationally sharing scarce collateral.

Our model provides precise predictions on the direction of capital flows and their effect on asset prices. Global capital flows in equilibrium are: (i) optimistic Foreign investors buy Home 
assets (capital flows to Home and assets flow to Foreign); (i) moderate Home investors buy Foreign assets (capital flows to Foreign); (iii) pessimistic Foreign investors buy risk-free assets from Home (capital flows to Home). ${ }^{12}$ The effect on asset valuation is subtle. The asset price at Home stays pretty stable while the asset price at Foreign increases after trade (see Section 3.1.5 for robustness).

To understand these effects better, consider the effect of financial trade on marginal buyers. As a result of financial integration, the marginal buyers of both assets increase. First, moderate Home investors (though more optimistic than the autarkic marginal buyer of $Y^{*}$ ) seek to buy the Foreign asset, which increases both the marginal buyer and the asset price. Second, optimistic Foreign investors desire to buy the Home asset with leverage, and this increases the marginal buyer. Investors in both countries achieve the same amount of leverage, but investors in Home, who are endowed with the more expensive asset, buy more units of the asset because they start with more wealth $\left(\hat{p}>\hat{p}^{*}\right)$. However, while the marginal buyer of the Home asset increases, the effect on the price of the Home asset is complicated by the fact that the alternative investment (the Foreign asset) is more attractive. Leveraged investors are now comparing the leveraged return to a (very attractive to them) un-leveraged return in the Foreign asset. Thus, even though the marginal investor is more optimistic, the required return is higher and so the asset price decreases. There are two opposing forces: greater optimism and a more attractive investment alternative. The overall effect on the Home price is ambiguous. ${ }^{13}$ After financial integration there is still a gap in prices between Home and Foreign assets due to the Home asset role as collateral. However, this gap is smaller than the one observed in autarky.

\subsubsection{Comparative Statics and Testable Implications}

We provide comparative statics by varying the shape of the beliefs function $\gamma(i)$ and the down payoff $d_{D}^{Y}$. We parametrize beliefs by $\gamma(i)=i^{\zeta}$, where $\zeta$ determines the relative frequency of optimism/pessimism, which is equivalent to the relative demand for positive/negative-beta assets.

\footnotetext{
${ }^{12}$ Notice that Foreign wealth has increased $\left(1+p^{*}<1+\hat{p}^{*}\right)$ and more investors hold risk-free assets $\left(i^{Y^{*}}<\hat{i}^{Y^{*}}\right)$, implying a greater demand for risk-free assets. Since the supply of $X^{*}$ has not changed, the demand is being met by debt backed by the Home asset.

${ }^{13}$ The "alternative return" force tends to dominate when the function $\gamma(i)$ is concave. The Home price can increase if $\gamma(i)$ is sufficiently convex.
} 
When $\zeta>1(\gamma(i)$ convex), the economy features high demand for negative-beta assets (many pessimists), and the reverse is true when $\zeta<1$. We consider $\zeta \in[.35,5]$ and vary $d_{D}^{Y} \in[.01, .75]$.

Figure 4 shows the percent changes in asset prices from financial integration with leverage for Home and Foreign asset prices given parameters $\left(\zeta, d_{D}^{Y}\right)$. As noted, financial integration always increases the Foreign asset price, with the largest increases $(\sim 12 \%)$ occurring for high $d_{D}^{Y}$ and moderate demand for negative-beta assets ( $\zeta$ around 2.5). Financial integration increases the Home asset price when $d_{D}^{Y}$ is sufficiently high (the collateral value is high), and is more likely to increase when the economy features high demand for negative-beta assets (high $\zeta$ ). However, price increases are at best very modest.

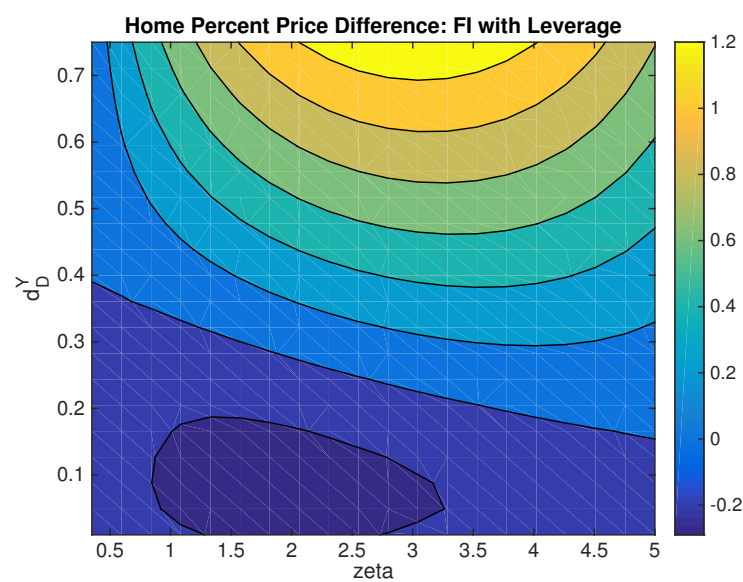

Home

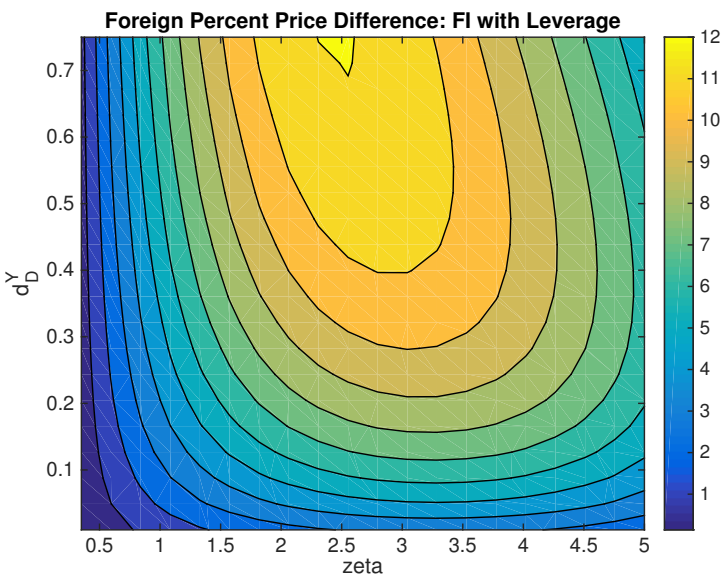

Foreign

Figure 4: Percent Changes in Asset Prices with Financial Integration with Leverage.

The comparative statics provide several testable implications. (i) Financial integration is more likely to increase asset prices for leverage-able Home assets with less downside risk (high $d_{D}^{Y}$ ). (ii) Financial integration increases Foreign asset prices more for assets with low downside risk and when the global demand for negative-beta assets is high but not extreme.

\subsection{Tranching and Global Flows}

We now suppose that the Home financial sector can create tranches using the risky asset as collateral. Without loss of generality, we suppose that $J$ consists of the single promise $j^{T}=\left(\left(0, d_{D}^{Y}\right), 1\right)$, 
which implies agents can completely tranche $Y .{ }^{14}$ We first consider the autarkic equilibria and then move on to consider the financial integration equilibrium. The autarky Foreign equilibrium is as described in Section 3.1.1, since changes in $J$ do not affect the Foreign economy.

\subsubsection{Autarky: Home}

The autarkic equilibrium at Home now features two marginal buyers, $i^{Y}$ and $i^{T}$. Agents $i>i^{Y}$ buy $Y$ and sell the down tranche $j^{T}=\left(0, d_{D}^{Y}\right)$ (effectively holding the Arrow $U$ security); agents $i^{T}<i<i^{Y}$ sell their endowment of $Y$ and purchase $X$; agents $i<i^{T}$ sell their assets $Y$ and $X$ and buy the down tranche $j^{T}=\left(0, d_{D}^{Y}\right)$, from the most optimistic investors (effectively buying the Arrow $D$ security). The equilibrium regime is shown in Figure 5.

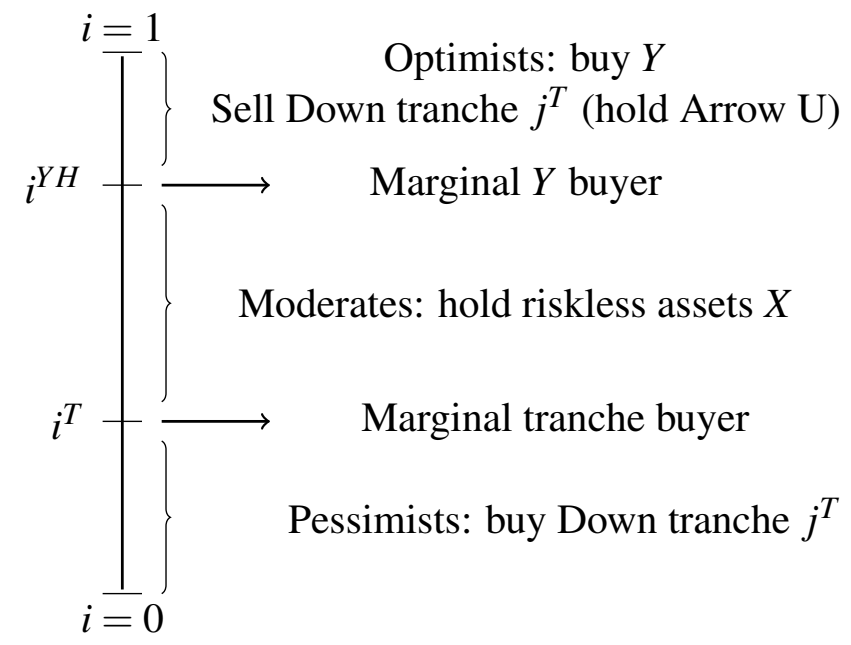

Figure 5: Equilibrium Regime with Tranching in Autarky.

Equilibrium is described by a system of four equations and four unknowns: the price of the

\footnotetext{
${ }^{14}$ A moment's reflection should convince the reader that in our two state economy, completely tranching $Y$ is tantamount to allowing the asset to back a promise of $d_{D}^{Y}$ in the down state. The asset holder on net then retains the $U$ Arrow security. By buying $y$ units of $Y$ and selling off $y$ units of the tranche $j^{T}=\left(0, d_{D}^{Y}\right)$, and also buying $z / d_{D}^{Y}$ units of the down tranche (perhaps created by somebody else), any agent who has enough wealth can effectively purchase the arbitrary consumption $c_{U}=y, c_{D}=z$. If it were possible to create different tranches beyond the two Arrow securities, no agent would have anything to gain by doing so. In the end his new tranches would not offer a potential buyer anything the buyer could not obtain for himself via the Arrow tranches, as we just saw. With unlimited and costless tranching, tranching into Arrow securities always drives out all alternative tranching schemes, a point made in Geanakoplos and Zame (2014). Since $j^{T}=\left(0, d_{D}^{Y}\right)$ already embodies Arrow tranching, there is no reason to consider any more complicated tranching schemes.
} 
asset, $p$, the price of the down tranche $\pi^{T}$, and the two marginal buyers, $i^{Y}$ and $i^{T}$. Market clearing for the asset $Y$ and the tranche $j^{T}$ are

$$
1=\left(1-i^{Y}\right) \frac{(1+p)}{p-\pi^{T}}
$$

and

$$
i^{T}(1+p)=\pi^{T}
$$

The top $1-i^{Y}$ agents are buying the asset and selling off the down tranche: they each have wealth $1+p$ plus the revenue from the tranche sale $\pi^{T}$. The bottom $i^{T}$ agents spend their endowments to buy the tranche. There is 1 unit of total supply of the asset, implying there is one unit supply of the tranche. Optimality conditions are given by

$$
\begin{gathered}
\gamma\left(i^{Y}\right)=p-\pi^{T}, \\
\left(1-\gamma\left(i^{T}\right)\right) d_{D}^{Y}=\pi^{T} .
\end{gathered}
$$

In each state the value of the Arrow $U$ and $D$ securities created through tranching are correctly priced by the marginal agent. Despite the fact that both Arrow securities can be created through tranching the asset, markets are not complete because Arrow securities are created through the risky asset only.

For the same parameter values in equilibrium we get $i^{Y}=.58, i^{T}=.08, p=1$, and $\pi^{T}=.17$. The asset price is much higher even than it was with leverage. Tranching $Y$ creates contingent promises that are highly valued by low- $i$ investors. This more sophisticated scheme of using $Y$ to issue financial promises further increases its value as collateral, increasing its price.

\subsubsection{Financial Integration with Tranching}

We now suppose that Home and Foreign agents can trade assets and tranches, and any agent can issue tranches by using the Home asset $Y$ collateral. In equilibrium in each country there are three marginal buyers: $\hat{i}^{Y}$, who is indifferent between buying $Y$ against a tranche and buying $Y^{*}$ with 
cash, $\hat{i}^{Y^{*}}$, who is indifferent between buying $Y^{*}$ with cash and holding risk-free assets, and $\hat{i}^{T}$ who is indifferent between buying the Down tranche and holding risk-free assets. Investors in both countries with $i \geq \hat{i}^{Y}$ buy $Y$ and issue the down tranche using the asset as collateral (hence holding the Arrow $U$ security). Investors $i \in\left(\hat{i}^{Y^{*}}, \hat{i}^{Y}\right)$ buy $Y^{*}$ with cash. Investors with $i \in\left(\hat{i}^{T}, \hat{i}^{Y^{*}}\right)$ hold the riskless assets $X$ and $X^{*}$. Finally, investors $i \leq \hat{i}^{T}$ buy the down tranche (hence holding the Arrow $D)$.

Equilibrium is described by a system of six equations in six unknowns: the prices of the assets and the tranche, $\hat{p}, \hat{p}^{*}$, and $\hat{\pi}^{T}$, and the marginal buyers, $\hat{i}^{Y}, \hat{i}^{Y^{*}}$, and $\hat{i}^{T}$. The equations for the marginal valuation and market clearing for the Foreign asset and for the tranche are given by equations (7), (9), (13), and (14).

$$
\hat{i}^{T}\left(2+\hat{p}+\hat{p}^{*}\right)=\hat{\pi}^{T}
$$

The marginal buyer $\hat{i}^{Y}$ is indifferent between the leveraged return on $Y$, issuing a down tranche, and the un-leveraged return $Y^{*}$ :

$$
\frac{\gamma\left(\hat{i}^{Y}\right) \times 1}{\hat{p}-\hat{\pi}^{T}}=\frac{\gamma\left(\hat{i}^{Y}\right)+\left(1-\gamma\left(\hat{i}^{Y}\right)\right) d_{D}^{Y}}{\hat{p}^{*}}
$$

The market clearing condition for the Home asset is

$$
1=\left(1-\hat{i}^{Y}\right) \frac{\left(2+\hat{p}+\hat{p}^{*}\right)}{\hat{p}-\hat{\pi}^{T}} .
$$

The equilibrium for the same parameter values is summarized in Table 2. Figure 6 illustrates the effects of financial integration on marginal investors and financial flows.

Table 2: Equilibrium Prices with Tranching.

\begin{tabular}{l|c|c} 
& Autarky & Integration $\left(^{\wedge}\right)$ \\
\hline Home Asset Price: $p$ & 1 & $1.021 \uparrow$ \\
Foreign Asset Price: $p^{*}$ & .834 & $.848 \uparrow$ \\
Down Tranche Price: $\pi^{T}$ & .168 & $.182 \uparrow$
\end{tabular}




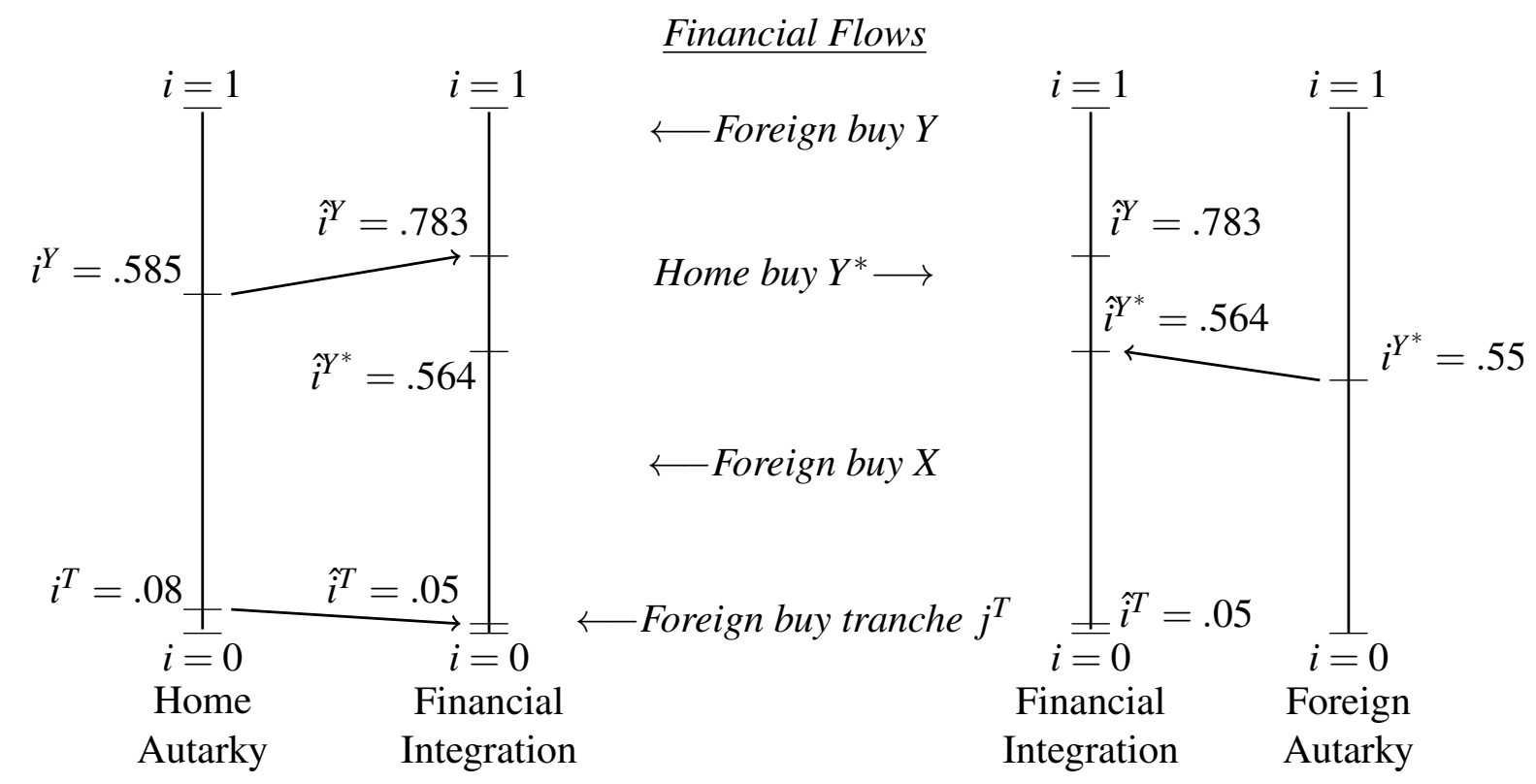

Figure 6: Equilibrium with Financial Integration and Tranching.

\subsubsection{Tranching and Global Flows}

As with the case of leverage differences in the ability to collateralize financial promises across borders are enough to generate international capital flows, and our model provides precise prediction on the direction of capital flows and effect on asset prices. First, financial flows that result from integration are as follows: (i) optimistic Foreign investors buy Home assets and sell the down tranche (capital flows to Home and assets flow to Foreign); (ii) moderate Home investors buy Foreign assets (capital flows to Foreign); (iii) pessimistic Foreign investors buy tranches backed by Home assets and some of the riskless Home asset. ${ }^{15}$ Second, both risky asset prices increase after financial integration.

\footnotetext{
${ }^{15}$ We also considered a model in which Home and Foreign agents have different beliefs, denoted by $\gamma(i)$ and $\gamma^{*}(i)$, in which case flows would occur even when countries have identical financial systems. When beliefs differ, asset flows depend on the relative frequency of optimists and pessimists. The country with relatively more optimists $(\gamma(i)$ is more convex) buys more assets and the country with relatively more pessimists buys more tranches. (A country could have relatively more of both optimists and pessimists while the other has more moderates, in which case the first country would buy both assets and tranches while the second would hold risk-free assets.) When countries have different financial systems, the flows that are generated by belief differences are concentrated in the Home asset, which can be tranched or leveraged, while the holdings of the Foreign asset are more similar across countries.
} 
There are two main differences with respect to financial integration with leverage in Section 3.1: Foreign investors buy Down tranches from Home, and the price of the Home risky asset increases compared to autarky. Consider again the effect of financial trade on marginal buyers. As before, the marginal buyers of both risky assets increase, and the marginal buyer of the tranche decreases, which increases the price of the tranche and increases the collateral value of the Home asset. Notice that the asset price is given by

$$
\hat{p}=\gamma\left(\hat{i}^{Y}\right) 1+\left(1-\gamma\left(\hat{i}^{T}\right)\right) d_{D}^{Y}
$$

which we get from combining equations (12) and (13). Foreign demand for the asset increases $\hat{i}^{Y}$, and foreign demand for the tranche decreases $\hat{i}^{T}$. The increase in the collateral value of the Home asset due to financial integration outweighs the "alternative investment return" effect we discussed before. As a result of financial integration, pessimistic Foreign investors demand down tranches, which pushes up their price (with leverage, the demand for risk-free assets did not change the riskfree price). Now, more-expensive tranches increases the value of the Home asset. In other words, financial integration increases the value of the promise backed by collateral when the promise is contingent, which is otherwise not available to Foreign agents in autarky.

Finally, while the Down tranche is a state-contingent security (and therefore very risky), we interpret the creation of Down tranches as related to the the creation of "safe assets," which as it turns out tend to increase in value in bad states of the world: negative-beta assets are truly safe assets. First, long-maturity bonds increase in price in bad states because long-term interest rates decline (even as the face value of the promised payoffs remain the same). Second, because the US Dollar tends to appreciate during crises, dollar-denominated bonds provide a natural hedge for foreign buyers. This is a point made in Maggiori (2013), which, in a different financial context, describes the rest of the world buying "down state" Arrow securities from Home in order to achieve safer portfolios. 


\subsubsection{Comparative Statics and Testable Implications}

We again provide comparative statics by varying the shape of the beliefs function $\gamma(i)$ and the down payoff $d_{D}^{Y}$. Figure 7 shows the percent changes in asset prices from financial integration with tranching. The behavior of the Foreign asset is similar as to with leverage, except the percent increases are slightly moderated. In contrast, the Home asset price increases everywhere for our range of parameters, and the key determinant of the percent increase is the demand for negativebeta assets $(\zeta)$, with greater increases $(10-12 \%)$ occurring when demand for negative-beta assets is high.

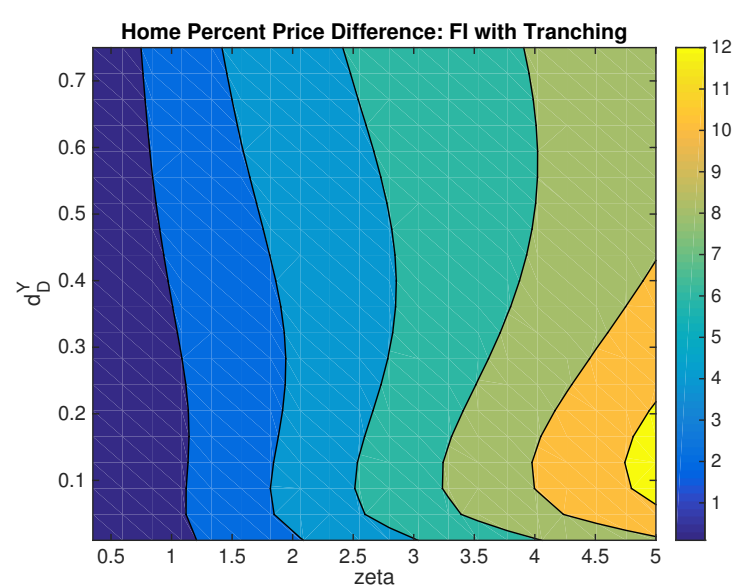

Home

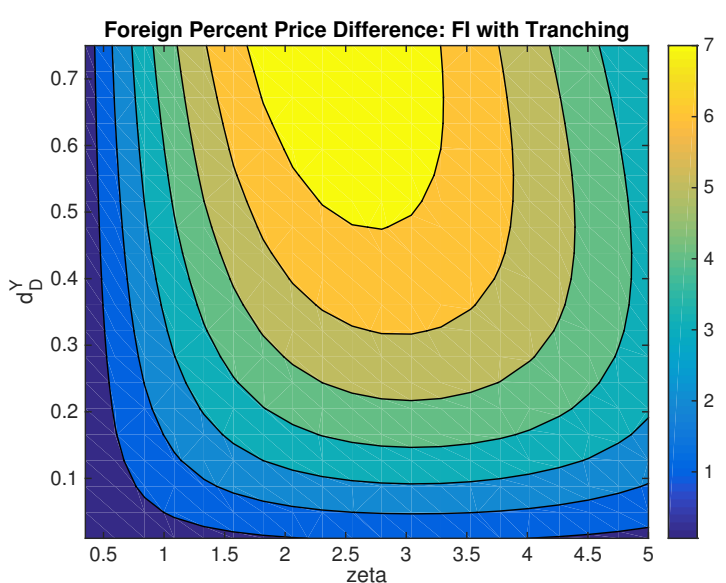

Foreign

Figure 7: Percent Changes in Asset Prices with Financial Integration with Tranching.

The comparative statics provide several testable implications. (i) Financial integration is more likely to increase asset prices for tranche-able Home assets when the global economy features high demand for negative-beta assets. (ii) As before, Financial integration increases Foreign asset prices more for assets with low downside risk and when the global demand for negative-beta assets is high but not extreme.

\subsection{Welfare in Static Models}

Financial integration has important implications for asset prices and global flows, but also for welfare. In this section we show how financial integration affects welfare for agents in each coun- 
try. Because of heterogeneity, different investors are affected differently by financial integration. We calculate the welfare for each agent $i$ using $i$ 's subjective probability $\gamma(i)$, using the baseline parametrization from earlier.

\subsubsection{Financial Integration and Leverage}

Figure 8 plots welfare in autarky and with financial integration, for each investor in Home and Foreign, when Home can leverage assets.

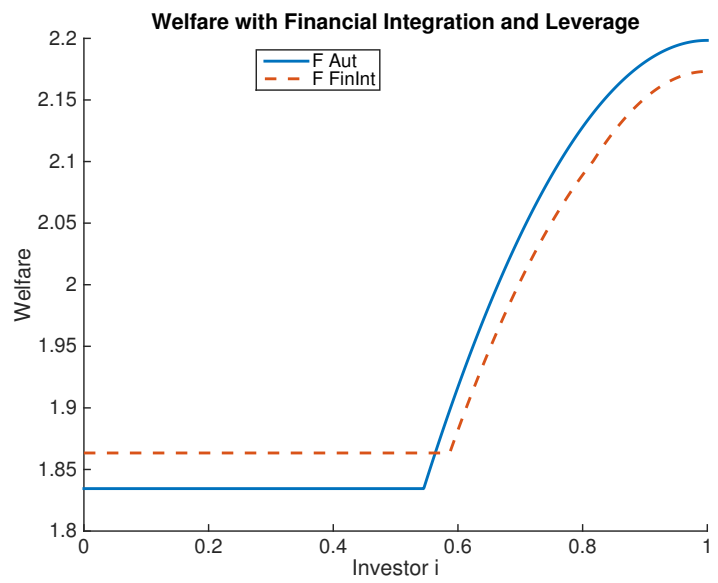

Foreign

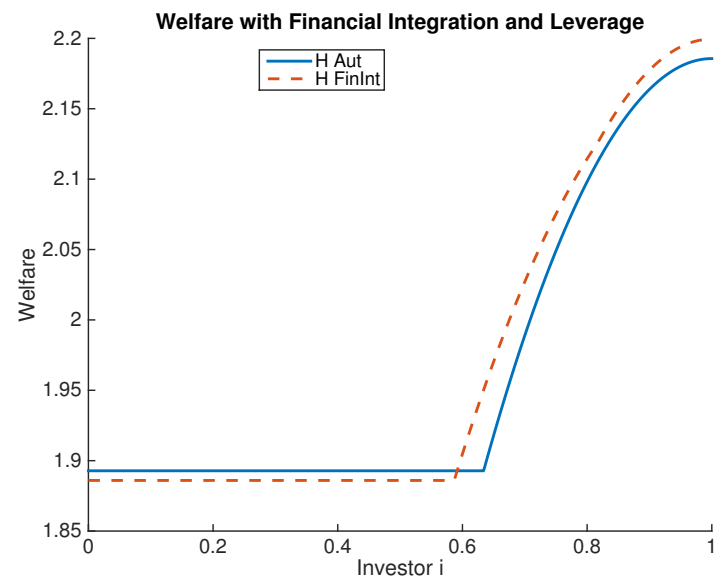

Home

Figure 8: Welfare Changes with Financial Integration and Leverage.

Given the equilibrium changes in prices, financial integration hurts Foreign optimists but benefits Home optimists. This is because these agents are buying risky assets. Home optimists benefit because the Home asset price decreases, making it easier for Home investors to buy, and the cheap Foreign asset offers a better alternative to risk-free assets. Foreign optimists are hurt because the prices of risky assets are higher with financial integration, even though Foreign investors prefer access to the Home, collateralizable, asset. For some parameters the Home price increases, in which case nearly all Home investors benefit from integration.

In contrast, financial integration benefits pessimists in Foreign, who now have higher wealth with which to buy safe assets (the Foreign asset price increased). Home pessimists are slightly worse off because their wealth is lower (the Home asset price decreased). 


\subsubsection{Financial Integration and Tranching}

Figure 9 plots welfare in autarky and with financial integration, for each investor in Home and Foreign, when Home can tranche assets.

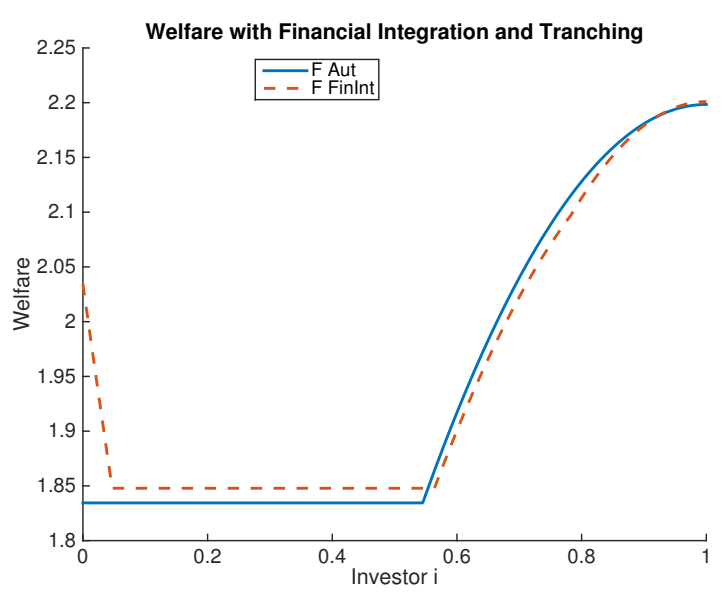

Foreign

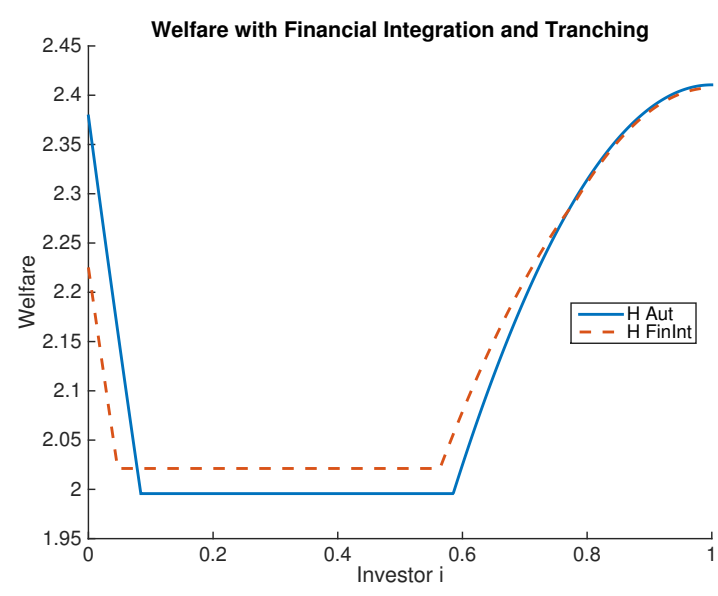

Home

Figure 9: Welfare Changes with Financial Integration and Tranching.

Compared to the economy with leverage, financial integration with tranching has similar effects for Foreign investors. With tranching, Foreign pessimists benefit by even more because of the availability of state-contingent down tranches, which offer much more attractive payoffs. Furthermore, optimists are almost negligibly affected by financial integration for two reasons. First, the change in the Foreign asset price is smaller, and so agents buying $Y^{*}$ are not so affected. Second, the ability to tranche $Y$ is comparatively more attractive than simply leveraging $Y$, and so agents buying $Y$ and issuing a down tranche can even be better off.

In contrast, financial integration hurts Home pessimists and optimists. This is because the prices of the assets they buy (down tranches, and "Arrow Up" through the purchase of $Y$ ) increase due to foreign demand. Moderates, however, are made better off by financial integration because their wealth increases and they buy risk-free assets, the price of which has not changed. 


\section{A Dynamic Model of Global Flows}

The static models illustrate how financial integration affects financial flows and how prices and marginal investors are affected. In this section we examine how the behavior of international flows affect volatility. We consider a dynamic model following Geanakoplos (2003), which demonstrates that asset prices become more volatile when assets can be used as collateral, and the collateral value of assets fluctuates in response to fundamentals. The main results of this section are that financial integration exports volatility from Home to Foreign, and when financial integration involves trade in tranches, it amplifies overall volatility.

We consider a dynamic variation of the model with three periods, $t=0,1,2$. Uncertainty in the payoffs of $Y$ and $Y^{*}$ is represented by a tree $S=\{0, U, D, U U, D U, D D\}$ illustrated in Figure 10. The assets in each country pay identical dividends in each state, which come only in $t=2$.

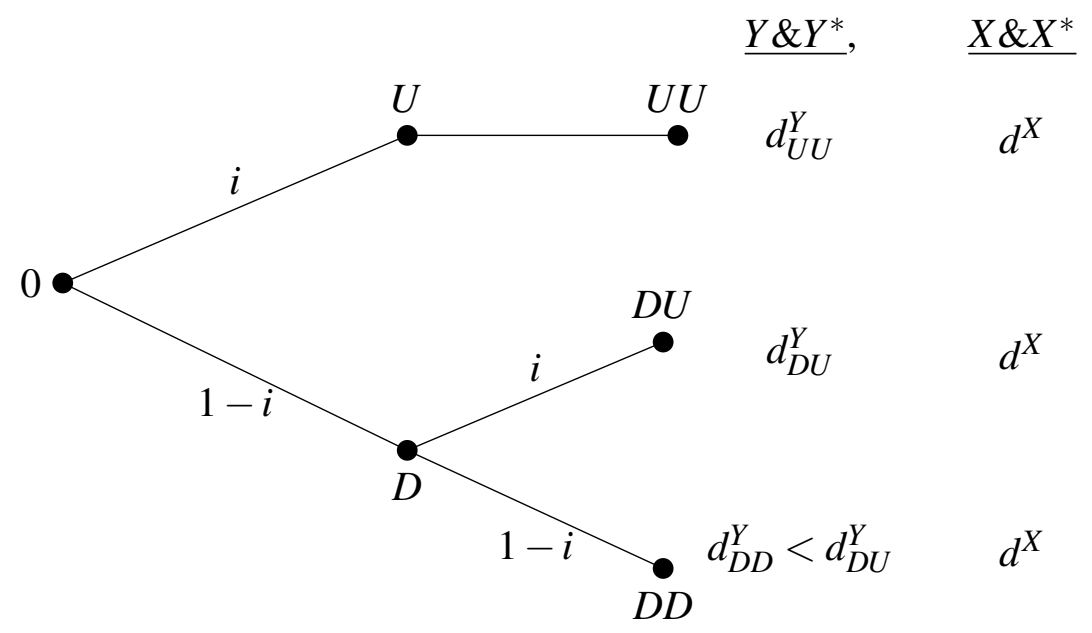

Figure 10: Asset Payoffs with Three Periods.

Agents consume only at the terminal nodes. The von-Neumann-Morgenstern expected utility to agent $i$ is

$$
U^{i}\left(c_{U U}, c_{D U}, c_{D D}\right)=i c_{U U}+i(1-i) c_{D U}+(1-i)^{2} c_{D D}
$$

As before, agents have endowments of the assets only at time 0 .

In light of Fact 4 regarding co-movement and propagation, the reader may wonder about our 
assumption of perfectly correlated assets. First, our results could generalize to when assets are imperfectly correlated so long as investors' valuations are correlated (optimists about Home assets are optimists about Foreign assets, see Fostel and Geanakoplos 2008). Second, and more importantly, our results highlight that financial integration amplifies financial shocks and exports volatility across countries. Thus, in the presence of other shocks (trade, import prices, productivity, etc.), financial shocks become more significant, given the higher volatility, and so financial shocks will tend to transmit through financial integration.

In the remainder of the paper we will solve and present equilibrium for the following parameters: agents utilities and endowments in both countries are given by $\gamma(i)=i .{ }^{16}$ Agents endowments at 0 are as before, $e^{Y}=e^{X}=1$, and asset payoffs in both countries are given by and $d^{X}=d_{U U}^{Y}=d_{D U}^{Y}=1$ and $d_{D D}^{Y}=.2$. As in Section 3 we will first study when Home can leverage and then when Home can tranche the risky asset.

\subsection{Leverage Cycle and Dynamic Global Flows}

We first consider when the Home economy can leverage the risky asset $Y$ to issue non-contingent promises. We describe the autarky equilibrium in each country and then describe the equilibrium with financial integration. For expositional ease, all equations for this section are provided in Appendix B.

\subsubsection{Autarky: Foreign}

Even though the economy is dynamic, the autarky equilibrium for Foreign is essentially the same as the static equilibrium described in Section 3. Denote the asset price in each state by $p_{0}^{*}$ and $p_{D}^{*}$. Agents choose portfolios of $Y^{*}$ and $X^{*}$ at $s=0$ and $s=D$, taking into account that in $D$ they can rebalance their portfolio with an asset price $p_{D}^{*}$. However, given the monotonicity of beliefs, in $s=0$ investors will hold all their wealth either in $X$ or the risky asset. In $s=D$, the wealth of investors who bought the risky asset will have decreased, but these investors are the optimistic

\footnotetext{
${ }^{16}$ Notice that the beliefs at $s=0$ about payoffs at $t=2$ correspond to the static models with beliefs $\gamma(i)=1-(1-$ $i)^{2}$.
} 
agents who continue to want to hold the risky asset, and so they do not choose to sell the asset. Because all of their wealth is in the asset, they do not have any other resources they can use to buy more of the asset at its low price. In other words, all agents will hold the same portfolios in $D$ as they did at $s=0$.

As a result, in both states there is a single marginal agent, $i_{0}^{Y^{*}}=i_{D}^{Y^{*}}$, and all agents $i>i_{0}^{Y^{*}}$ buy-and-hold the risky asset to maturity. The asset is thus priced by the marginal agent according to the payoff distribution at each state. For the parameter values considered before in equilibrium we get $i_{0}^{Y^{*}}=.545, p_{0}^{*}=.834$, and $p_{D}^{*}=.636$. The price falls in $D$ because the bad payoff is more likely; however, there are no amplifying mechanisms. The price crashes by $23.77 \%$.

\subsubsection{Autarky: Home}

With leverage the dynamic equilibrium is essentially different from the static equilibrium, though the equilibrium regimes in each state resemble the equilibrium regime in the static economy of Section 3. Denote the asset price in each state by $p_{0}$ and $p_{D}$. The implication of Proposition 1 in the dynamic model is that the only contract traded at time $s=0$ is the the $\max \min j^{*}=p_{D}$, and at $s=D$ is $j^{*}=d_{D}^{Y}$ (the worst case scenario avoiding default in both cases).

In $s=0$ there is a marginal buyer $i_{0}^{Y}$ such that all investors with $i>i_{0}^{Y}$ buy $Y$ on margin promising $p_{D}$. Crucially, in state $D$ all investors that bought the risky asset on margin go bankrupt (they owe all the asset value and have no other wealth). This means that the asset must be bought by more pessimistic investors $i \in\left[0, i_{0}^{Y}\right]$. In state $D$ there is a marginal buyer $i_{D}^{Y}$, such that all remaining investors with $i>i_{D}^{Y}$ buy $Y$ with leverage by borrowing $d_{D}^{Y}$ against each unit of the asset. For the same parameters the equilibrium is given by: $p_{0}=.958, p_{D}=.69, i_{0}^{Y}=.86, i_{D}^{Y}=.61$.

The price crashes by $27.91 \%$, greater than the crash in Foreign precisely because of the amplifying mechanisms due to leverage. This is what Geanakoplos (2003) called the Leverage Cycle. The asset price falls in the Down state for three reasons: first, fundamentals are worse (a bad payoff is more likely); second, the equilibrium margin increases in state $\mathrm{D}$, and so investors use less leverage and the marginal buyer is therefore less optimistic; third, investors who used leverage in the first period go bankrupt in the Down state as a result of the margin call. These optimistic buyers- 
the most optimistic buyers - have no wealth available after repaying their debt, which leaves less optimistic investors to buy the asset. The changes in the marginal buyer and in equilibrium leverage create excess volatility; the price drops by more than can be attributed to fundamentals alone. ${ }^{17}$

\subsubsection{Leverage Cycle and Financial Integration}

We now suppose that Home and Foreign agents can trade assets and bonds, and any agent can use the Home asset $Y$ as collateral in order to borrow. As in the static model, some investors in both countries will choose to hold $Y$ with leverage, while some will choose to hold $Y^{*}$ without leverage. In $s=D$ the amplifying mechanisms from leverage will cause the marginal buyer of $Y$ to fall as leveraged agents go bankrupt and margins increase. Importantly, a decrease in the marginal investor in $Y$ will decrease the marginal investor for $Y^{*}$, even though the Foreign asset is not leveraged. The amplification in the volatility of the Foreign asset is entirely driven by dynamic global flows.

In period 0 there are two marginal buyers $\hat{i}_{0}^{Y}$ and $\hat{i}_{0}^{Y^{*}}$ in both countries. The most optimistic investors, with $i \geq \hat{i}_{0}^{Y}$, buy $Y$ with leverage. Intermediate buyers with $i \in\left[\hat{i}_{0}^{Y^{*}}, \hat{i}_{0}^{Y}\right)$ hold $Y^{*}$ unleveraged; some of these investors hold $Y^{*}$ to maturity, while some will sell $Y^{*}$ to buy $Y$ in state $D$. The most pessimistic investors, with $i<\hat{i}_{0}^{Y^{*}}$, hold risk-free claims, either $X$ or riskless debt. In $D$ there are two marginal buyers $\hat{i}_{D}^{Y}$ and $\hat{i}_{D}^{Y^{*}}$ in both countries. The optimists holding $Y$ go bankrupt because of the margin call. The new buyers of $Y$, with $i \in\left[\hat{i}_{D}^{Y}, \hat{i}_{0}^{Y}\right)$, are investors who held $Y^{*}$ in 0 . However, their purchasing power is impaired because the price of the Foreign asset has decreased. Some of the $Y^{*}$ investors continue to hold their investment, but the most optimistic of the $Y^{*}$ investors dump the asset in $D$ to buy $Y$. The remaining $Y^{*}$ is bought by investors, with $i \in\left[\hat{i}_{D}^{Y^{*}}, \hat{i}_{0}^{Y^{*}}\right)$ who held riskless claims at $s=0$.

Denote the asset prices in each state by $\hat{p}_{0}, \hat{p}_{0}^{*}, \hat{p}_{D}, \hat{p}_{D}^{*}$. Table 3 shows the equilibrium asset prices in autarky and with financial integration. Figure 11 displays marginal investors.

\footnotetext{
${ }^{17}$ Fostel and Geanakoplos (2014) present an equivalent model with two agents with heterogeneous risk-aversion and endowments. There is an equivalent mechanism which corresponds to a change in optimism of the marginal buyer. In a two-agent model, the marginal buyer is the same but the wealth of the marginal buyer decreases in the bad state, increasing the marginal utility of consumption and causing the investor to discount future payments by more.
} 
Table 3: Leverage Cycle and Financial Integration.

\begin{tabular}{l|c|c} 
& Autarky & Integration $\left(^{\wedge}\right)$ \\
\hline$p_{0}$ & .958 & $.948 \downarrow$ \\
$p_{0}^{*}$ & .834 & $.888 \uparrow$ \\
$p_{D}$ & .69 & $.696 \uparrow$ \\
$p_{D}^{*}$ & .636 & $.659 \uparrow$ \\
crash in $Y$ & $27.91 \%$ & $26.63 \% \downarrow$ \\
crash in $Y^{*}$ & $23.77 \%$ & $25.8 \% \uparrow$ \\
crash sum & $51.69 \%$ & $52.43 \% \uparrow$
\end{tabular}

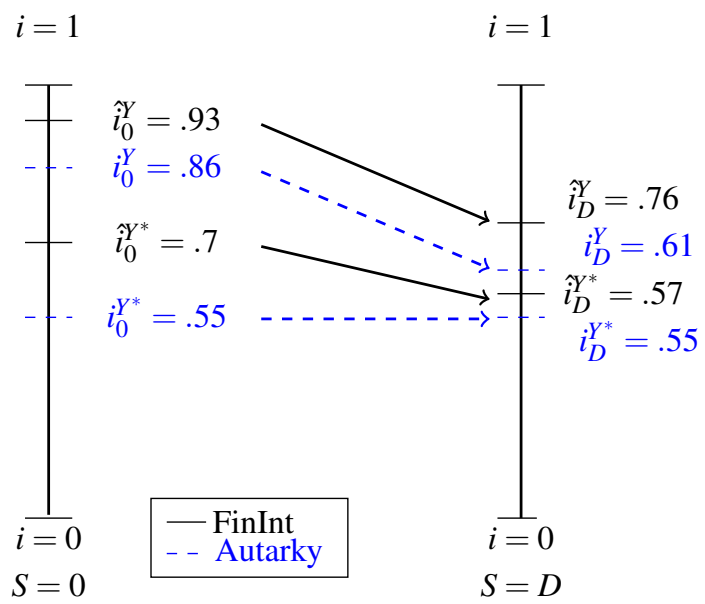

Figure 11: Marginal Investors with Financial Integration and Leverage. In autarky the Foreign marginal buyer is the same across states, $i_{0}^{Y^{*}}=i_{D}^{Y^{*}}=.55$ (no instability). With financial integration, the Foreign marginal buyer decreases after bad news (trade flows create instability), which is true for the Home buyer in autarky and with financial integration.

The crash is slightly moderated in the domestic country, but it is exacerbated in the Foreign country. ${ }^{18}$ The total volatility in autarky is $27.91+23.77=51.69$ and the total volatility with trade is slightly higher, $26.63+25.8=52.43$. Even though the Foreign asset is not leveraged, the price crash is almost as large as it is in the domestic asset. The Leverage Cycle becomes global.

\footnotetext{
${ }^{18}$ If the distribution of investors were not uniform, but so that the marginal asset buyers were closer to the extremes, the difference between the crashes with leverage and without would be much greater.
} 
As the price of $Y$ fluctuates, the relative attractiveness of investing in $Y^{*}$ fluctuates as well. Since $Y$ has excess volatility because it is bought with leverage, $Y^{*}$ has excess volatility. Notice that the state-0 Home asset price is lower with financial integration than in autarky, as was also true in the static model. However, the state- $D$ Home asset price is higher with financial integration. The relative attractiveness of the Foreign asset is lower in $D$ than it was at 0 , or in other words, collateral becomes more valuable when margins become tougher.

\subsection{Tranching and Dynamic Global Flows}

We now consider the ability of Home to tranche the risky asset. We first characterize the autarky equilibrium in Home to demonstrate how tranching affects dynamics, and then we consider the equilibrium with financial integration. The autarkic Foreign equilibrium is the same as in Section 4.1.1.

\subsubsection{Autarky: Home}

As in the leverage economy, the marginal investors will change from $s=0$ to $s=D$ as a result of bankruptcy and wealth distribution among agents. However, the Tranching cycle is even more volatile than the Leverage cycle of Section 4.1.2.

In equilibrium there are two marginal buyers in each state. In $s=0$, investors $i>i_{0}^{Y}$ buy the risky asset and issue a down tranche promising $p_{D}$; investors with $i<i_{0}^{T}$ buy the down tranche, which has a price $\pi_{0}^{T}$; the remaining moderate investors hold $X$. In $s=D$, investors $i>i_{0}^{Y}$ go bankrupt (they owe the whole value of the asset). There is a marginal buyer $i_{D}^{Y}$ such that all remaining investors $i>i_{D}^{Y}$ buy the asset and issue a down tranche promising $d_{D}^{Y}$. There is a marginal buyer $i_{D}^{T}$ such that all investors $i<i_{D}^{T}$ buy the down tranche, which has a price $\pi_{D}^{T}$. The remaining investors hold $X$ as before. For the same parameter values we get the following equilibrium:

$$
\begin{aligned}
& p_{0}=1.132, \quad p_{D}=.669, \quad i_{0}^{Y}=.708, \quad i_{D}^{Y}=.482, \\
& \pi_{0}^{T}=.509, \quad \pi_{D}^{T}=.186, \quad i_{0}^{T}=.239, \quad i_{D}^{T}=.067
\end{aligned}
$$


The price crash is now 41\%, much larger than in the leverage economy. Fostel and Geanakoplos (2012a) show that tranching adds an additional kick to the Leverage Cycle due to fluctuations in the the collateral value. The asset price with tranching price starts out higher than with leverage, 1.132 compared to .95 , due to its higher collateral value. Notice that at $s=D$ the asset price in both economies (tranching and leverage) is nearly the same, hence the fall is inversely related to the starting point.

\subsubsection{Financial Integration with Tranching}

We now suppose that Home and Foreign agents can trade assets and tranches, and any agent can issue tranches by using the Home asset $Y$ as collateral. In equilibrium in period 0 there are three marginal buyers $\hat{i}_{0}^{Y}, \hat{i}_{0}^{Y^{*}}$, and $\hat{i}_{0}^{T}$ in both countries. The most optimistic investors, with $i \geq \hat{i}_{0}^{Y}$, buy $Y$ selling the down tranche. Intermediate buyers with $i \in\left[\hat{i}_{0}^{Y^{*}}, \hat{i}_{0}^{Y}\right)$ hold $Y^{*}$ outright. The most pessimistic investors, with $i<\hat{i}_{0}^{Y^{T}}$, buy down tranches, and the rest hold risk-free $X$ and $X^{*}$.

After bad news, important wealth distributions takes place: the optimists holding $Y$ go bankrupt, the moderates holding $Y^{*}$ have impaired wealth, and the pessimists holding tranches have increased wealth. In $D$ there are three marginal buyers $\hat{i}_{D}^{Y}, \hat{i}_{D}^{Y^{*}}$, and $\hat{i}_{D}^{T}$ in both countries. The new buyers of $Y$, with $i \in\left[\hat{i}_{D}^{Y}, \hat{i}_{0}^{Y}\right)$, are investors who held $Y^{*}$ in 0 . However, their purchasing power is impaired because the price of the Foreign asset has decreased. Some of the $Y^{*}$ investors continue to hold their investment, but the most optimistic of the $Y^{*}$ investors dump the asset in $D$ to buy $Y$ while selling the down tranche. The remaining $Y^{*}$ is bought by investors, with $i \in\left[\hat{i}_{D}^{Y^{*}}, \hat{i}_{0}^{Y^{*}}\right)$ who held riskless assets at $s=0$. The most pessimistic investors, with $i<\hat{i}_{D}^{Y^{T}}$, buy down tranches.

The results are shown in Table 4. 
Table 4: Tranching Cycle and Financial Integration.

\begin{tabular}{l|c|c}
$s=0$ & Autarky & Integration $\left(^{\wedge}\right)$ \\
\hline$p_{0}$ & 1.132 & $1.33 \uparrow$ \\
$p_{0}^{*}$ & .834 & $.837 \uparrow$ \\
$\pi_{0}^{T}$ & .509 & $.62 \uparrow$ \\
$i_{0}^{Y}$ & .708 & $.831 \uparrow$ \\
$i_{0}^{Y^{*}}$ & .545 & $.63 \uparrow$ \\
$i_{0}^{T}$ & .239 & $.15 \downarrow$
\end{tabular}

\begin{tabular}{l|c|c}
$s=D$ & Autarky & Integration $\left({ }^{\wedge}\right)$ \\
\hline$p_{D}$ & .669 & $.734 \uparrow$ \\
$p_{D}^{*}$ & .636 & $.6 \downarrow$ \\
$\pi_{D}^{T}$ & .186 & $.192 \uparrow$ \\
$i_{D}^{Y}$ & .482 & $.65 \uparrow$ \\
$i_{D}^{Y^{*}}$ & .545 & $.5 \downarrow$ \\
$i_{D}^{T}$ & .067 & $.039 \downarrow$
\end{tabular}

\begin{tabular}{c|c|c} 
Price Crash & Autarky & Integration \\
\hline crash in $Y$ & $41 \%$ & $44.8 \% \uparrow$ \\
crash in $Y^{*}$ & $23.8 \%$ & $28.3 \% \uparrow$ \\
total & $64.7 \%$ & $73.1 \% \uparrow$
\end{tabular}

There is an even larger crash in the Home asset, and the crash in the Foreign asset price is larger than it was without tranching-larger even than the crash in the leverage economy in autarky. Tranching increases volatility everywhere. Financial integration has increased the value of tranching, which increased the collateral value of the Home asset and therefore increased the price volatility of the Home asset. ${ }^{19}$ Because the Foreign asset is priced relative to the Home asset, the Foreign asset is much more volatile as well. ${ }^{20}$

\subsection{Comparative Dynamics and Testable Implications}

We provide comparative dynamics by varying the down payoff $d_{D D}^{Y}$. Figure 12 plots the changes in global volatility with tranching as a function of the downside risk $d_{D D}^{Y}$. (The results for leverage are qualitatively similar.) The intuition for the relationship between $d_{D D}^{Y}$ and how financial integration affects volatility can be seen by considering the right frame, which plots price volatility in autarky. For low $d_{D D}^{Y}$, volatility is higher with leverage compared to no leverage, because in these cases there is a large decline in leverage after bad news. But when $d_{D D}^{Y}$ is sufficiently high, leverage

\footnotetext{
${ }^{19}$ Gong and Phelan (2016b) derive a similar result in a closed-economy setting by studying how equilibrium changes when debt contracts can be used as collateral to make financial promises ("debt collateralization"). They show that debt collateralization increases the collateral value of the risky asset and increases the volatility of asset prices.

${ }^{20}$ To isolate the effect of the increase in the collateral value, in Appendix A.1 we consider when countries can trade only in tranches but not in the risky assets. Because there is no trade in $Y^{*}$, the volatility of the Foreign asset does not increase relative to autarky. However, the volatility of the Home asset increases because of dynamic trade in tranches.
} 
dampens amplification because even after bad news investors are able to use leverage to prop up asset prices (the decline in leverage following bad news is less severe). In either case, volatility decreases as downside risk decreases.

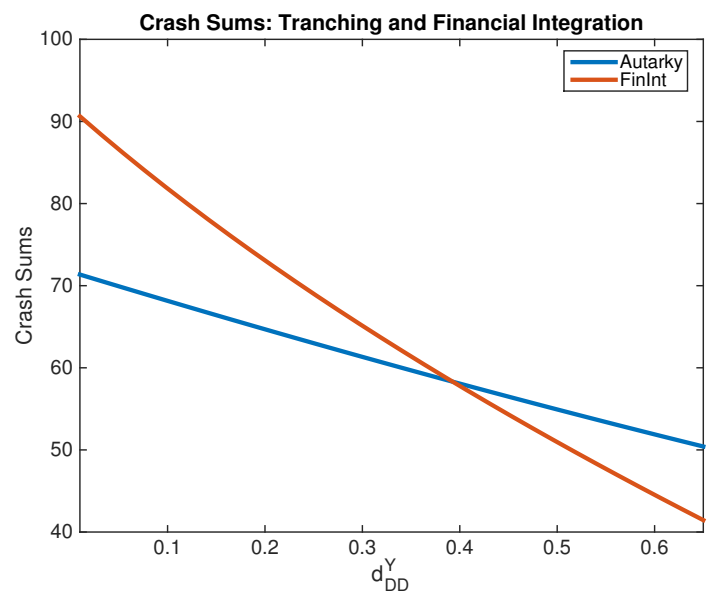

Financial Integration with Tranching

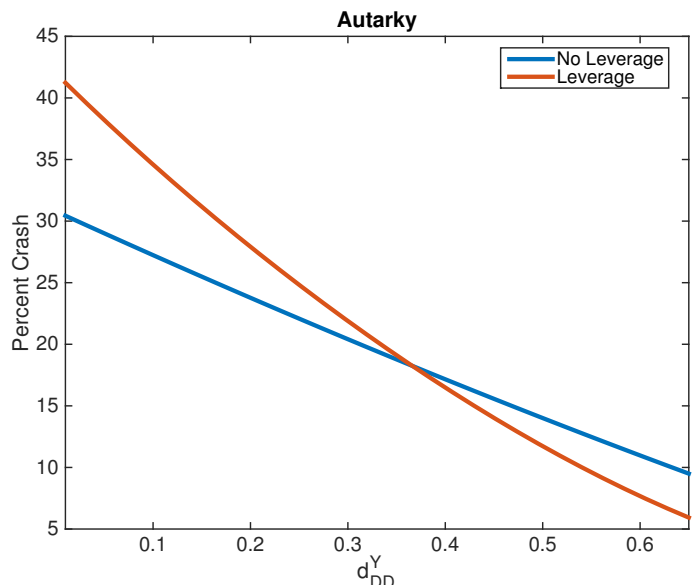

Autarky

Figure 12: Sensitivity of Price Volatility to Downside Risk.

As is clear, financial integration amplifies financial shocks whenever volatility is larger when the asset can be used as collateral. Put differently, for parameters in which leverage amplifies shocks, financial integration increases global volatility. Thus, financial integration amplifies volatility for large financial shocks (low $d_{D D}^{Y}$ ), but dampens volatility for small financial shocks (high $d_{D D}^{Y}$ ). These effects follow because financial integration is a way of sharing collateral, and thus of sharing financial innovation and its effects.

\subsection{Welfare in Dynamic Models}

Financial integration has important implications for asset price volatility, but also for welfare in the dynamic economy. In this section we show how financial integration affects welfare for agents in each country. We briefly summarize those results here. While financial integration with tranching leads to large amplification in asset price volatility in both countries, the consequences for welfare can actually be quite beneficial for many agents in both countries. Essentially all Foreign investors benefit from financial integration, and moderate Home investors benefit from financial integration. 
While many agents benefit from financial integration in this model, it is worth considering that asset price volatility can nonetheless be quite costly in reality. Our model leaves out many important factors, such as production, investment, cash flow problems, agency issues, and bankruptcy costs, just to name a few. Phelan (2016) uses a richer model to show that financial leverage creates a pecuniary externality through excess volatility, resulting in an economy with higher likelihood of crises and recessions and lower welfare. One can suspect that incorporating the mechanisms of our paper into a richer framework with any of the aforementioned issues would result in welfare losses from increased volatility.

\subsubsection{Financial Integration and Dynamic Leverage}

We calculate the welfare for each agent $i$ using $i$ 's subjective probability at each node. Figure 13 plots welfare in autarky and with financial integration for each investor in Home and Foreign.

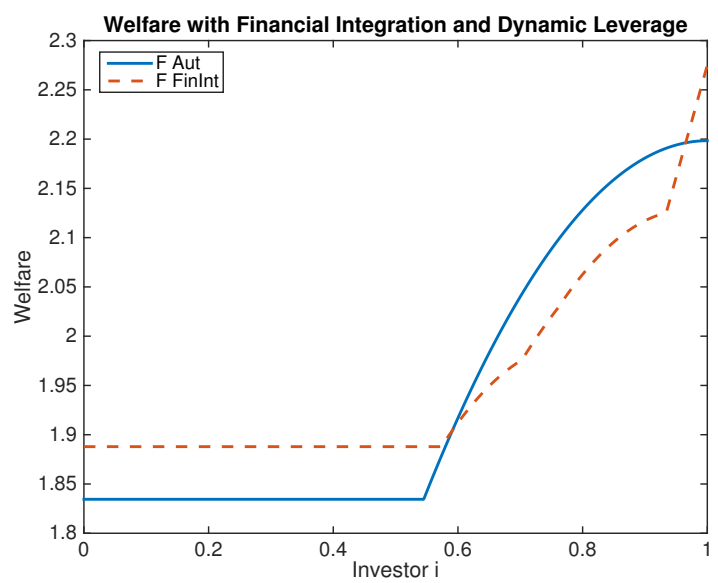

Foreign

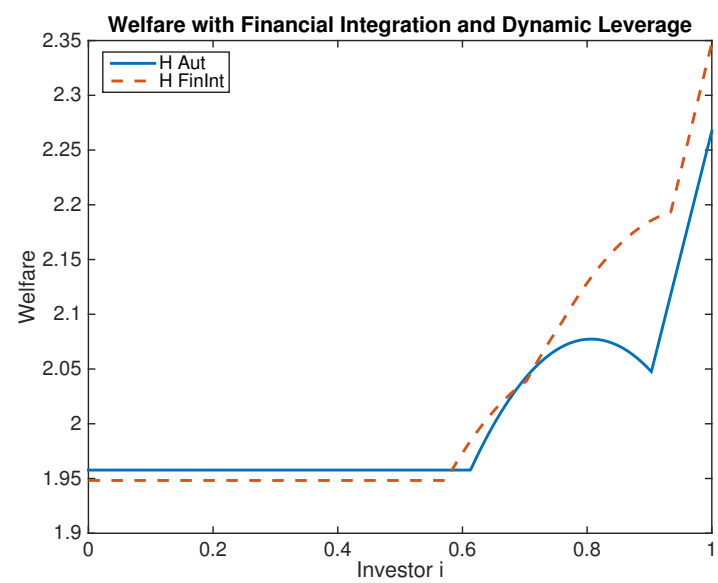

Home

Figure 13: Welfare Changes with Financial Integration and Dynamic Leverage.

In the leverage economy, the welfare results of financial integration are similar for the dynamic and static models. The key differences are that in the dynamic model, the most optimistic Foreign agents benefit from financial integration because the ability to take a leveraged position in $Y$ is doubly-valuable in the dynamic model, owing to greater leverage at time 0. As well, Foreign pessimists benefit comparatively more than in the static model because their increase in wealth is 
greater. Similarly, Home optimists benefit by more than in the static model because of the greater ability to leverage at time 0 (the price is lower at 0 and higher at $\mathrm{D}$, so that the downpayment at 0 is lower with financial integration), and because of the ability to hold the risky Foreign asset, instead of cash, at time 0 .

\subsubsection{Financial Integration and Dynamic Tranching}

Figure 14 plots welfare in autarky and with financial integration for each investor in Home and Foreign.

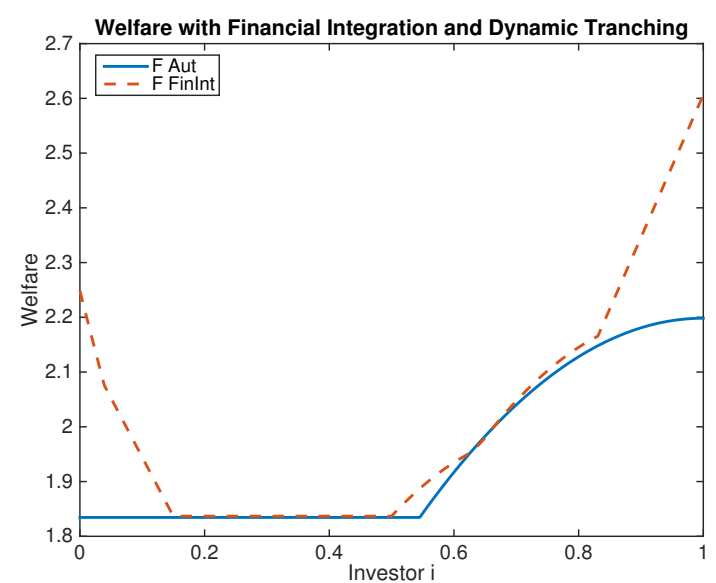

Foreign

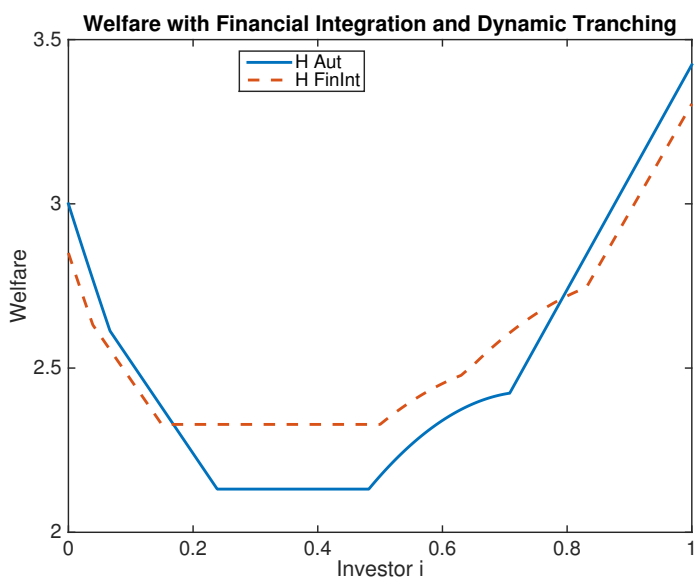

Home

Figure 14: Welfare Changes with Financial Integration and Dynamic Tranching.

Essentially all Foreign investors benefit from financial integration, which was not the case in the static model with tranching. Similarly, Home optimists are hurt by much less than in the static model and moderates benefit from financial integration by much more than in the static model. The mechanisms in each case are closely related to the ones discussed in the dynamic model with leverage. The benefit from tranching the asset at time 0 is amplified in the dynamic model owing to the change in the price of tranches at $s=D$. 


\section{Conclusion}

We have presented a two country general equilibrium model with collateralized lending and tranching in which global capital flows are driven by different levels of financial innovation across countries. Motivated by cross-country differences in collateralizability (Observation 4), we define financial innovation as the use of new assets as collateral or new kinds of financial promises that can be issued by collateral. Financial integration provides Foreign access to attractive Home financial assets, and cross-border flows arise in both directions in response to changes in the available financial contracts and as a result of general equilibrium changes in the prices of currently available assets (Observation 1). These flows arise as a way for countries to share scarce collateral and to trade contingent claims, including safe and negative beta assets (Observation 2). The resulting flows have important consequences for financial stability, exporting volatility abroad and amplifying volatility globally, because global flows are dynamic and adjust in response to fundamentals (Observation 3).

Our results have important policy implications. First, we highlight the importance of monitoring cross-border gross banking flows, since it is precisely the changes in these flows, even when they net out, that exacerbate and transmit volatility. Second, while there are benefits to accessing foreign financial markets, even for developed economies these benefits may come at the cost of importing financial volatility. Thus, while others have pointed out the trade-offs for emerging economies, we show that there may also be relevant trade-offs for mature economies. Macroprudential policy, even global macro-prudential policy, becomes critical.

\section{References}

ACHARYA, V. V. AND P. SChnABL (2010): "Do global banks spread global imbalances? Assetbacked commercial paper during the financial crisis of 2007-09," IMF Economic Review, 58, $37-73$.

Angeletos, G.-M. And V. PAnOusi (2011): "Financial Integration, Entrepreneurial Risk and Global Dynamics," Journal of Economic Theory, 146, 863-896. 
BeKaert, G. AND C. R. HARVEy (2000): "Foreign speculators and emerging equity markets," The Journal of Finance, 55, 565-613.

Bertaut, C., L. P. Demarco, S. Kamin, And R. Tryon (2012): “ABS inflows to the United States and the global financial crisis," Journal of International Economics, 88, 219-234.

BRUnO, V. AND H. S. ShIN (2014): “Cross-border banking and global liquidity," The Review of Economic Studies, rdu042.

Caballero, R. J., E. Farhi, and P.-O. Gourinchas (2008): “An Equilibrium Model of “Global Imbalances” and Low Interest Rates,” American Economic Review, 98, 358-93.

Calza, A., T. Monacelli, And L. STRACCA (2007): "Mortgage markets, collateral constraints, and monetary policy: do institutional factors matter?" Collateral Constraints, and Monetary Policy: Do Institutional Factors Matter.

Cerqueiro, G., S. Ongena, And K. Roszbach (2014): “Collateralization, Bank Loan Rates, and Monitoring," The Journal of Finance, n/a-n/a.

DAVIS, J. S. (2014): “Financial integration and international business cycle co-movement," Journal of Monetary Economics, 64, 99-111.

Devereux, M. B. AND J. Yetman (2010): "Leverage constraints and the international transmission of shocks," Journal of Money, Credit and Banking, 42, 71-105.

Forbes, K. J. And F. E. WARnock (2012): "Capital flow waves: Surges, stops, flight, and retrenchment," Journal of International Economics, 88, 235-251.

Fostel, A. And J. Geanakoplos (2008): "Leverage Cycles and The Anxious Economy," American Economic Review, 98, 1211-1244.

- (2012a): "Tranching, CDS, and Asset prices: How Financial Innovation Can Cause Bubbles and Crashes," American Economic Journal: Macroeconomics, 4, 190-225. 
_ (2012b): “Why Does Bad News Increase Volatility And Decrease Leverage?” Journal of Economic Theory, 147, 501-525.

(2014): "Endogenous collateral constraints and the leverage cycle," Annu. Rev. Econ., 6, $771-799$.

- (2015): "Leverage and default in binomial economies: a complete characterization," Econometrica, 83, 2191-2229.

(2016): "Financial Innovation, Collateral, and Investment," American Economic Journal: Macroeconomics, 8, 242-284.

Geanakoplos, J. (1997): "Promises Promises," in Santa Fe Institute Studies in the Sciences of Complexity-proceedings volume, Addison-Wesley Publishing Co, vol. 27, 285-320.

(2003): "Liquidity, Default and Crashes: Endogenous Contracts in General Equilibrium," in Advances in Economics and Econometrics: Theory and Applications, Eight World Conference, Econometric Society Monographs, vol. 2, 170-205.

GEANAKOPlos, J. AND W. R. ZAME (2014): “Collateral equilibrium, I: a basic framework,” Economic Theory, 56, 443-492.

Gong, F. AND G. Phelan (2016a): “A Collateral Theory of the Cash-Synthetic Basis,” Working Paper, Williams College.

- (2016b): “Debt Collateralization, Capital Structure, and Maximal Leverage,” Working Paper, Williams College.

Hale, G. AND M. OBSTFELd (2016): “The Euro and the geography of international debt flows," Journal of the European Economic Association, 14, 115-144.

IMBS, J. (2006): “The real effects of financial integration,” Journal of International Economics, 68, 296-324. 
Kalemli-OzCan, S., E. PAPAioannou, And F. PerRi (2013): “Global banks and crisis transmission," Journal of international Economics, 89, 495-510.

Kalemli-OzCAn, S., B. Sorensen, And S. Yesiltas (2012): "Leverage across firms, banks, and countries," Journal of international Economics, 88, 284-298.

Kose, M. A., C. Otrok, And C. H. Whiteman (2008): "Understanding the evolution of world business cycles," Journal of international Economics, 75, 110-130.

LAne, P. R. And G. M. Milesi-Ferretti (2007): “The external wealth of nations mark II: Revised and extended estimates of foreign assets and liabilities, 1970-2004," Journal of international Economics, 73, 223-250.

LOUTSKinA, E. AND P. E. STRAHAN (2015): "Financial integration, housing, and economic volatility," Journal of Financial Economics, 115, 25-41.

MAGGIORI, M. (2013): "Financial intermediation, international risk sharing, and reserve currencies," Mimeo.

MendozA, E. G. AND V. QUADRINI (2010): "Financial globalization, financial crises and contagion," Journal of monetary economics, 57, 24-39.

Mendoza, E. G., V. QuAdrini, And J.-V. Rios-Rull (2009): "Financial intergration, financial development, and global imbalances," Journal of Political Economy, 117, 3.

NGUYEN, H. AND R. QIAN (2012): “The cross-country magnitude and determinants of collateral borrowing," World Bank Policy Research Working Paper.

ObStFELd, M. (2012): "Financial flows, financial crises, and global imbalances," Journal of International Money and Finance, 31, 469 - 480, financial Stress in the Eurozone.

Phelan, G. (2015): “Collateralized Borrowing and Increasing Risk,” Economic Theory, 1-32. (2016): "Financial intermediation, leverage, and macroeconomic instability," American Economic Journal: Macroeconomics, 8, 199-224. 
Phelan, G. And A. A. TodA (2016): "Securitized Markets, International Capital Flows, and Global Welfare,” Mimeo.

SANTIS, G. AND B. GERARD (1997): "International asset pricing and portfolio diversification with time-varying risk," The Journal of Finance, 52, 1881-1912.

SHIN, H. S. (2012): “Global Banking Glut and Loan Risk Premium,” IMF Economic Review, 60, $155-192$.

UEDA, K. (2012): "Banking globalization and international business cycles: Cross-border chained credit contracts and financial accelerators," Journal of international Economics, 86, 1-16.

WARnOCK, F. E. AND V. C. WARnOCK (2012): "Developing Housing Finance Systems," in Reserve Bank of Australia Annual Conference Volume, vol. 16.

WARNOCK, V. C. AND F. E. WARNOCK (2008): "Markets and housing finance," Journal of Housing economics, 17, 239-251.

WILlEN, P. (2004): “Incomplete markets and trade,” Tech. rep., FRB of Boston Working Paper.

\section{Appendices}

\section{A Other Financial Environments}

\section{A.1 Financial Integration with Trade in Tranches but Not Assets}

Suppose that countries can trade financial promises backed by collateral but not the asset itself. In this case, only Home investors can buy the Home asset, but there is Foreign demand for the tranches backed by the asset, and so there will be trade in tranches. There will be trade in the down tranche, so we refer to this case as "T-Trade." This will have no effect on the price of the Foreign asset, which is purchased without leverage, but it will increase the price of the Home asset. The 
Home asset is bought by issuing a down tranche against the collateral. Trade in the tranche will increase the price of the tranche and thus increase the amount of assets that Home investors can purchase using tranching.

In equilibrium, there is a marginal Home investor for the Home asset, $i^{Y}$, and all Home investors with $i \geq i^{Y}$ buy $Y$ by issuing a down tranche in order to borrow. There is a marginal investor for the Foreign asset $i^{Y^{*}}$ and all Foreign investors with $i \geq i^{Y^{*}}$ buy $Y^{*}$ without leverage. There is a marginal investor $i^{T}$ such that all Home and Foreign investors with $i \leq i^{T}$ buy the down tranche. Intermediate (moderate) Home investors with $i \in\left(i^{T}, i^{Y}\right)$ and Foreign investors $i \in\left(i^{T}, i^{Y^{*}}\right)$ hold the riskless assets $X, X^{*}$. Optimists buy assets, moderates hold debt, pessimists hold tranches.

Because there is no trade in assets, the marginal valuations and market clearing conditions for $Y, Y^{*}$ are as they were in the respective situations in autarky, i.e., given by equations (2), (3), (10), and (12). The conditions for the tranche are given by equations (13) and (14).

The static equilibrium with $\gamma(i)=1-(1-i)^{2}$ and $d_{D}^{Y}=.2$ is summarized in Table 5 , and the dynamic equilibrium is summarized in Table 6.

Table 5: Equilibrium Prices and Marginal Investors when Home Country Tranches Assets.

\begin{tabular}{l|c|c} 
& Autarky & T-Trade \\
\hline$p$ & 1 & 1.011 \\
$p^{*}$ & .834 & .834 \\
$p^{A D}$ & .84 & .91 \\
$i^{Y}$ & .585 & .587 \\
$i^{Y^{*}}$ & .545 & .545 \\
$i^{T}$ & .084 & .0472
\end{tabular}


Table 6: Tranching Cycle with T-Trade and TY-Trade.

Time-0

\begin{tabular}{l|c|c|c} 
& Autarky & T-Trade & TY-Trade \\
\hline$p_{0}$ & 1.132 & 1.172 & 1.33 \\
$p_{0}^{*}$ & .834 & .834 & .837 \\
$p_{0}^{A D}$ & .761 & .861 & .85 \\
$i_{0}^{Y}$ & .708 & .717 & .831 \\
$i_{0}^{Y^{*}}$ & .545 & .545 & .63 \\
$i_{0}^{T}$ & .239 & .139 & .15
\end{tabular}

\begin{tabular}{l|c|c|c}
\multicolumn{4}{c}{ State-D } \\
& Autarky & T-Trade & TY-Trade \\
\hline$p_{D}$ & .669 & .646 & .734 \\
$p_{D}^{*}$ & .636 & .636 & .6 \\
$p_{D}^{A D}$ & .933 & .959 & .96 \\
$i_{D}^{Y}$ & .482 & .454 & .65 \\
$i_{D}^{Y^{*}}$ & .545 & .545 & .5 \\
$i_{D}^{T}$ & .067 & .041 & .039
\end{tabular}

\begin{tabular}{c|c|c|c} 
& Autarky & T-Trade & TY-Trade \\
\hline Crash in $Y$ & $41 \%$ & $44.9 \%$ & $44.8 \%$ \\
Crash in $Y^{*}$ & $23.8 \%$ & $23.8 \%$ & $28.3 \%$ \\
total & $64.7 \%$ & $68.7 \%$ & $73.1 \%$
\end{tabular}

With trade in tranches but not assets (T-trade), excess volatility is being driven by the change in the marginal buyer of the down security. In state $\mathrm{D}$, the tranche gets bid up because pessimists believe the ultimate bad state is more likely and pessimists are wealthy because they bought a down security last period, which just paid off big. The equilibrium allocations are as in the 2period static economy, but the marginal buyers for $Y$ for the tranche change in state $D$. Because there is no trade in assets, there is no effect on the marginal buyer or the price of the Foreign asset. The marginal buyer of the Home asset changes because of the Leverage Cycle. How much the marginal leveraged investor changes depends on trade because the price of the tranche changes, reflecting foreign demand for the tranche.

\section{A.2 Leverage, Tranching and Global Flows}

In this section the Home financial sector can tranche assets and the Foreign financial sector can leverage, but not tranche, assets, and countries can trade both assets and tranches. We refer to this case as "TL-trade." Unlike in the other environments, we do not have segmented markets for Home and Foreign assets. To see this, suppose an investor is considering buying $Y$ with leverage 
against a tranche and buying $Y^{*}$ with leverage against debt. The returns to these options are

$$
\gamma(i) \frac{1}{p-p^{A D} d_{D}^{Y}}, \quad \gamma(i) \frac{1-d_{D}^{Y}}{p^{*}-d_{D}^{Y}}
$$

which are both multiplicative in the investor's belief. So if any investor $i^{Y}$ prefers $Y$ over $Y^{*}$, every investor with $i>i^{Y}$ will, too, and no investor would prefer the alternative. Thus, in equilibrium there is a marginal buyer $i^{Y}$ that is willing to hold both assets, implying $\frac{1}{p-p^{A D} d_{D}^{Y}}=\frac{1-d_{D}^{Y}}{p^{*}-d_{D}^{Y}}$. Investors with $i \geq i^{Y}$ hold both assets. Define the fractions $\phi, \phi^{*}$ of wealth devoted to each asset; market clearing requires $\left(1-i^{Y}\right) \phi \frac{2+p+p^{*}}{p-p^{A D} d_{D}^{Y}}=1$ and $\left(1-i^{Y}\right) \phi^{*} \frac{2+p+p^{*}}{p^{*}-d_{D}^{Y}}=1 .{ }^{21}$ Equilibrium is summarized in Table 7.

Table 7: Equilibrium when Home Tranches Assets and Foreign Leverages Assets.

\begin{tabular}{l|c|c} 
& Autarky & TL-Trade \\
\hline$p$ & 1 & .965 \\
$p^{*}$ & .893 & .827 \\
$p^{A D}$ & .84 & .907 \\
$i^{Y}$ & .63 & .535 \\
$i^{Y^{*}}$ & .545 & .535 \\
$i^{T}$ & .084 & .0478
\end{tabular}

Surprisingly, trade decreases the prices of all assets. This is because the attractiveness of alternative investments increases for both Home and Foreign investors since both investors compare investing in the asset to a leveraged return rather than cash (either "leveraging against a tranche" or leveraging against debt). Since high prices are often symptomatic of financial fragility (propped up by leverage), one might be inclined to think that this economy is more stable. After all, prices are not propped up as much and perhaps have less far to fall. However, the static effects mask the dynamic consequences.

\footnotetext{
${ }^{21}$ With the previous equation, this implies that the shares satisfy $\phi=\frac{1-d_{D}^{Y}}{2-d_{D}^{Y}}$ and $\phi^{*}=\frac{1}{2-d_{D}^{Y}}$.
} 


\section{Dynamic Leverage and Tranching Cycle}

When Home can tranche assets and Foreign can leverage but only against debt, this situation creates important dynamics because now every investor, whether buying the Home or Foreign assets, goes bankrupt in $D$. Since initial prices are low and the marginal investor is low, more optimistic investors go bankrupt than before. We saw in the two-period model that the marginal investor is much lower with trade in this situation, and this means that there are even more defaults in $D$ than ever before. Equilibrium is summarized in Table 8.

Table 8: Leverage and Tranching Cycle.

\begin{tabular}{|c|c|c|c|c|c|c|}
\hline \multicolumn{4}{|c|}{ Time- 0} & \multicolumn{3}{|c|}{ State-D } \\
\hline & Autarky & \multicolumn{2}{|c|}{ TL-Trade } & \multirow[b]{2}{*}{$p_{D}$} & Autarky & TL-Trade \\
\hline$p_{0}$ & 1.132 & \multicolumn{2}{|l|}{1.10} & & .669 & .619 \\
\hline$p_{0}^{*}$ & .958 & \multicolumn{2}{|l|}{.801} & $p_{D}^{*}$ & .69 & .542 \\
\hline$p_{0}^{A D}$ & .761 & \multicolumn{2}{|l|}{.907} & $p_{D}^{A D}$ & .933 & .958 \\
\hline$i_{0}^{Y}$ & .708 & \multicolumn{2}{|l|}{.673} & $i_{D}^{Y}$ & .482 & .43 \\
\hline$i_{0}^{Y^{*}}$ & .86 & \multicolumn{2}{|l|}{.673} & $i_{D}^{Y^{*}}$ & .61 & .43 \\
\hline \multirow[t]{5}{*}{$i_{0}^{T}$} & .239 & \multicolumn{2}{|l|}{.137} & $i_{D}^{T}$ & .041 & .042 \\
\hline & & & Autark & & L-Trade & \\
\hline & & Crash & $41 \%$ & & $43.8 \%$ & \\
\hline & & -Crash & $27.91 \%$ & & $32.4 \%$ & \\
\hline & & total & $68.91 \%$ & & $76.2 \%$ & \\
\hline
\end{tabular}

Prices are more volatile in both countries. This is a warning that macro-prudential policy must consider the nature of financial entanglements and cannot simply look at asset prices as a proxy for brewing instability. If anything, it is low initial prices, allowing more investors to buy the assets with leverage, that plant the seeds of instability.

\section{A.3 A Model with Exchange Rates}

We now extend the model to study the determination of exchange rates and how exchange rates affect flows and asset prices in equilibrium. The main result is that with home-bias, financial innovation appreciates the Home currency. 
Consider two differentiated goods, one produced by Home, $c_{H}$, and the other produced by Foreign, $c_{F}$. The Home asset delivers units of the Home consumption good $c_{H}$, and the Foreign asset delivers units of the Foreign consumption good $c_{F}$. Agents in both countries have preferences over a CES aggregate of the two goods, so that utility is over a basket of goods given by

$$
C=\left(\omega\left(c_{H}\right)^{1-\frac{1}{\sigma}}+(1-\omega)\left(c_{F}\right)^{1-\frac{1}{\sigma}}\right)^{\frac{1}{1-\frac{1}{\sigma}}}, \quad C^{*}=\left((1-\omega)\left(c_{H}^{*}\right)^{1-\frac{1}{\sigma}}+\omega\left(c_{F}^{*}\right)^{1-\frac{1}{\sigma}}\right)^{\frac{1}{1-\frac{1}{\sigma}}}
$$

where $\sigma$ is the elasticity across goods, and where $\omega \in\left[\frac{1}{2}, 1\right)$ potentially allows for bias in each country's preferences toward its domestic good. The utility specification in equation (1) is over the aggregate consumption $C$ and $C^{*}$.

Let the price of the Home good $c_{H}$ be $q_{U}$ and $q_{D}$ in states $U$ and $D$, and let the price of the Foreign $\operatorname{good} c_{F}$ be normalized to 1 in each state (i.e., $q_{U}^{*}=q_{D}^{*}=1$ ). Because the price of domestic consumption goods are not normalized, we cannot normalize the price of $X$, which we denote $p_{X}$, and which will be determined endogenously in equilibrium.

In the absence of trade costs, the cost of consumption bundle $\left(c_{H}, c_{F}\right)$ in state $s$ is $c_{H} q_{s}+c_{F}$. Standard static optimization implies

$$
c_{F}=c_{H}\left(\frac{q_{s}(1-\omega)}{\omega}\right)^{\sigma}, \quad c_{F}^{*}=c_{H}^{*}\left(\frac{q_{s} \omega}{(1-\omega)}\right)^{\sigma} .
$$

If investors spend $W_{s}$ and $W_{s}^{*}$ on consumption goods in state $s$, then from the budget constraints we get

$$
c_{H, s}=\frac{W_{s}}{q_{s}+\left(\frac{q_{s}(1-\omega)}{\omega}\right)^{\sigma}}, \quad c_{H, s}^{*}=\frac{W_{s}^{*}}{q_{s}+\left(\frac{q_{s} \omega}{(1-\omega)}\right)^{\sigma}} .
$$

Notice that from market clearing conditions Home and Foreign investors in the aggregate buy a fraction of all the assets in the economy, with each fraction given by

$$
w=\frac{p_{X}+p}{p_{X}+p+1+p^{*}}, \quad w^{*}=\frac{1+p^{*}}{p_{X}+p+1+p^{*}}=1-w
$$

The total value of dividends paid by assets in $U$ is $2 q_{U}+2$, and the total value of dividends paid in $D$ is $q_{U}\left(1+d_{D}^{Y}\right)+1+d_{D}^{Y}$. This implies that in $U$ Home investors in aggregate spend $W_{U}=$ 
$w\left(2\left(q_{U}+1\right)\right)$ and Foreign investors in the aggregate spend $W_{U}^{*}=w^{*}\left(2\left(q_{U}+1\right)\right)$. Market clearing for good $c_{H}$ in $U, c_{H, U}+c_{H, U}^{*}=2$, can thus be written as

$$
\frac{W_{U}}{q_{U}+\left(\frac{q_{U}(1-\omega)}{\omega}\right)^{\sigma}}+\frac{W_{U}^{*}}{q_{U}+\left(\frac{q_{U} \omega}{(1-\omega)}\right)^{\sigma}}=2 \Longrightarrow \frac{w}{q_{U}+\left(\frac{q_{U}(1-\omega)}{\omega}\right)^{\sigma}}+\frac{(1-w)}{q_{U}+\left(\frac{q_{U} \omega}{(1-\omega)}\right)^{\sigma}}=\frac{1}{q_{U}+1} .
$$

Similarly, market clearing for good $c_{H}$ in $D$ yields

$$
\frac{w}{q_{D}+\left(\frac{q_{D}(1-\omega)}{\omega}\right)^{\sigma}}+\frac{(1-w)}{q_{D}+\left(\frac{q_{D} \omega}{(1-\omega)}\right)^{\sigma}}=\frac{1}{q_{D}+1}
$$

Since these equations are identical except for the price variable, this implies that $q_{U}=q_{D}=q$, the price of the home consumption good is the same in both states. This also implies that $p_{X}=q$.

We can easily characterize the equilibrium price as a function of $\omega$. When $\omega=\frac{1}{2}$ so that there is no domestic bias, $q=1$ and equilibrium asset prices are the same as when there is a single homogeneous consumption good. This is not the case when there is domestic bias, $\omega>\frac{1}{2}$. Because Home investors are wealthier (remember that $p>p^{*}$ ), the domestic bias implies that the Home consumption good will be more expensive, $q>1$. This also increases the prices of the Home assets $X$ and $Y$ since these pay dividends in the more expensive consumption good. Notice that $q>1$ implies that the Home currency is stronger than the Foreign currency, a result that is driven entirely by the ability to leverage or tranche collateral.

\section{B Equilibrium Conditions for Dynamic Economies}

\section{Autarky Leverage}

Let $J=J^{Y}$. Denote by $i_{0}^{Y}, i_{D}^{Y}$ the marginal buyers in periods 0 and 1 . The equilibrium conditions with leverage and no trade are

$$
\left(1-i_{0}^{Y}\right) \frac{1+p_{0}}{p_{0}-p_{D}}=1
$$




$$
\begin{aligned}
& \left(i_{0}^{Y}-i_{D}^{Y}\right) \frac{1+p_{0}}{p_{D}-d_{D}^{Y}}=1 \\
& \frac{i_{0}^{Y}\left(1-p_{D}\right)}{p_{0}-p_{D}}=i_{0}^{Y}+\left(1-i_{0}^{Y}\right) \frac{i_{0}^{Y}\left(1-d_{D}^{Y}\right)}{p_{D}-d_{D}^{Y}} \\
& i_{D}^{Y}+\left(1-i_{D}^{Y}\right) d_{D}^{Y}=p_{D}
\end{aligned}
$$

\section{Y-Trade}

With trade, the marginal buyers in period 0 are $\left(\hat{i}_{0}^{Y}, \hat{i}_{0}^{Y^{*}}\right)$ and in $\mathrm{D}$ are $\left(\hat{i}_{D}^{Y}, \hat{i}_{D}^{Y^{*}}\right)$. The period- 0 conditions are straightforward from before:

$$
\begin{aligned}
& \left(1-\hat{i}_{0}^{Y}\right) \frac{2+\hat{p}_{0}+\hat{p}_{0}^{*}}{\hat{p}_{0}-\hat{p}_{D}}=1 \\
& \left(\hat{i}_{0}^{Y}-\hat{i}_{0}^{Y^{*}}\right) \frac{2+\hat{p}_{0}+\hat{p}_{0}^{*}}{\hat{p}_{0}^{*}}=1 \\
& \frac{\hat{i}_{0}^{Y}\left(1-\hat{p}_{D}\right)}{\hat{p}_{0}-\hat{p}_{D}}=\frac{\hat{i}_{0}^{Y}}{\hat{p}_{0}^{*}}+\frac{\left(1-\hat{i}_{0}^{Y}\right) \hat{p}_{D}^{*}}{\hat{p}_{0}^{*}} \frac{\hat{i}_{0}^{Y}\left(1-d_{D}^{Y}\right)}{\hat{p}_{D}-d_{D}^{Y}} \\
& \frac{1-\left(1-\hat{i}_{0}^{Y^{*}}\right)^{2}\left(1-d_{D}^{Y}\right)}{\hat{p}_{0}^{*}}=\hat{i}_{0}^{Y^{*}}+\left(1-\hat{i}_{0}^{Y^{*}}\right) \frac{\hat{i}_{0}^{Y^{*}}+\left(1-\hat{i}_{0}^{Y^{*}}\right) d_{D}^{Y}}{\hat{p}_{D}^{*}}
\end{aligned}
$$

$$
\begin{aligned}
& \frac{\hat{i}_{0}^{Y}-\hat{i}_{D}^{Y}}{\hat{i}_{0}^{Y}-\hat{i}_{0}^{Y *}} \frac{\hat{p}_{D}^{*}}{\hat{p}_{D}-d_{D}^{Y}}=1 \\
& \frac{\hat{i}_{D}^{Y}-\hat{i}_{0}^{Y^{*}}}{\hat{i}_{0}^{Y}-\hat{i}_{0}^{Y^{*}}}+\frac{\hat{i}_{0}^{Y^{*}}-i_{D}^{Y^{*}}}{p_{D}^{*}}\left(2+\hat{p}_{0}+\hat{p}_{0}^{*}\right)=1 \\
& \frac{\hat{i}_{D}^{Y}\left(1-d_{D}^{Y}\right)}{\hat{p}_{D}-d_{D}^{Y}}=\frac{\hat{i}_{D}^{Y}+\left(1-\hat{i}_{D}^{Y}\right) d_{D}^{Y}}{\hat{p}_{D}^{*}} \\
& \hat{i}_{D}^{Y^{*}}+\left(1-\hat{i}_{D}^{Y^{*}}\right) d_{D}^{Y}=\hat{p}_{D}^{*}
\end{aligned}
$$

\section{Autarky Tranching}

Denote by $i_{0}^{Y}, i_{0}^{T}, i_{D}^{Y}, i_{D}^{T}$ the marginal buyers in state 0 and $D$. The equilibrium conditions with tranching and no trade are 


$$
\begin{aligned}
& \left(1-i_{0}^{Y}\right) \frac{\left(1+p_{0}\right)}{p_{0}-p_{D} p_{0}^{A D}}=1 \\
& i_{0}^{T}\left(1+p_{0}\right)=p_{D} p_{0}^{A D} \\
& \frac{i_{0}^{Y}}{p_{0}-p_{D} p_{0}^{A D}}=i_{0}^{Y}+\left(1-i_{0}^{Y}\right) \frac{i_{0}^{Y}}{p_{D}-d_{D}^{Y} p_{D}^{A D}} \\
& 1-i_{0}^{T}=p_{0}^{A D} \\
& p_{D}-d_{D}^{Y} p_{D}^{A D}=\left(i_{0}^{Y}-i_{D}^{Y}\right)\left(1+p_{0}\right) \\
& \frac{i_{D}^{T} p_{D}=d_{D}^{Y} p_{D}^{A D}}{i_{0}^{T}} \\
& \frac{i_{D}^{Y}}{p_{D}-d_{D}^{Y} p_{D}^{A D}}=1 \\
& 1-i_{D}^{T}=p_{D}^{A D}
\end{aligned}
$$

\section{T-Trade}

Eleven variables: $\hat{i}_{0}^{Y}, \hat{i}_{D}^{Y}, \hat{i}_{0}^{Y^{*}}, \hat{i}_{0}^{T}, \hat{i}_{D}^{T}, \hat{p}_{0}, \hat{p}_{0}^{*}, \hat{p}_{0}^{A D}, \hat{p}_{D}, \hat{p}_{D}^{*}, \hat{p}_{D}^{A D}$. Because the Foreign asset cannot be leveraged, the marginal buyer in 0 and $D$ are the same. 3 Market clearing in 0,3 valuation in 0,2 market clearing in D, 3 valuation in D.

$$
\begin{aligned}
& \left(1-\hat{i}_{0}^{Y}\right) \frac{\left(1+\hat{p}_{0}\right)}{\hat{p}_{0}-\hat{p}_{D} \hat{p}_{0}^{A D}}=1 \\
& p_{0}^{*}=\left(1-\hat{i}_{0}^{Y^{*}}\right)\left(1+\hat{p}_{0}^{*}\right) \\
& \hat{i}_{0}^{T}\left(2+\hat{p}_{0}+\hat{p}_{0}^{*}\right)=\hat{p}_{D} \hat{p}_{0}^{A D} \\
& \frac{\hat{i}_{0}^{Y}}{\hat{p}_{0}-\hat{p}_{D} \hat{p}_{0}^{A D}}=\hat{i}_{0}^{Y}+\left(1-\hat{i}_{0}^{Y}\right) \frac{\hat{i}_{0}^{Y}}{\hat{p}_{D}-d_{D}^{Y} \hat{p}_{D}^{A D}} \\
& \hat{p}_{0}^{*}=1-\left(1-\hat{i}^{Y^{*}}\right)^{2} d_{D}^{Y} \\
& 1-\hat{i}_{0}^{T}=\hat{p}_{0}^{A D} \\
& \hat{p}_{D}-d_{D}^{Y} \hat{p}_{D}^{A D}=\left(\hat{i}_{0}^{Y}-\hat{i}_{D}^{Y}\right)\left(1+\hat{p}_{0}\right)
\end{aligned}
$$




$$
\begin{aligned}
& \frac{\hat{i}_{D}^{T}}{\hat{i}_{0}^{T}} \hat{p}_{D}=d_{D}^{Y} \hat{p}_{D}^{A D} \\
& \frac{\hat{i}_{D}^{Y}}{\hat{p}_{D}-d_{D}^{Y} \hat{p}_{D}^{A D}}=1 \\
& \hat{p}_{D}^{*}=\hat{i}^{Y^{*}}+\left(1-\hat{i}^{Y^{*}}\right) d_{D}^{Y} \\
& 1-\hat{i}_{D}^{T}=\hat{p}_{D}^{A D} ;
\end{aligned}
$$

\section{TY-Trade}

Twelve variables: $\hat{i}_{0}^{Y}, \hat{i}_{D}^{Y}, \hat{i}_{0}^{Y^{*}}, \hat{i}_{D}^{Y^{*}}, \hat{i}_{0}^{T}, \hat{i}_{D}^{T}, \hat{p}_{0}, \hat{p}_{0}^{*}, \hat{p}_{0}^{A D}, \hat{p}_{D}, \hat{p}_{D}^{*}, \hat{p}_{D}^{A D} .3$ Market clearing in 0,3 valuation in 0,3 market clearing in $\mathrm{D}, 3$ valuation in $\mathrm{D}$.

$$
\begin{aligned}
& \left(1-\hat{i}_{0}^{Y}\right) \frac{2+\hat{p}_{0}+\hat{p}_{0}^{*}}{\hat{p}_{0}-\hat{p}_{D} \hat{p}_{0}^{A D}}=1 \\
& \hat{p}_{0}^{*}=\left(\hat{i}_{0}^{Y}-\hat{i}_{0}^{Y^{*}}\right)\left(2+\hat{p}_{0}+\hat{p}_{0}^{*}\right) \\
& \hat{i}_{0}^{T}\left(2+\hat{p}_{0}+\hat{p}_{0}^{*}\right)=\hat{p}_{D} \hat{p}_{0}^{A D} \\
& \frac{\hat{i}_{0}^{Y}}{\hat{p}_{0}-\hat{p}_{D} \hat{p}_{0}^{A D}}=\frac{\hat{i}_{0}^{Y}}{\hat{p}_{0}^{*}}+\frac{1-\hat{i}_{0}^{Y}}{\hat{p}_{0}^{*}} \frac{\hat{i}_{0}^{Y}}{\hat{p}_{D}-d_{D}^{Y} \hat{p}_{D}^{A D}} \\
& \frac{1-\left(1-\hat{i}^{Y^{*}}\right)^{2} d_{D}^{Y}}{\hat{p}_{0}^{*}}=\hat{i}_{0}^{Y^{*}}+\left(1-\hat{i}_{0}^{Y^{*}}\right) \frac{\hat{i}_{0}^{Y^{*}}+\left(1-\hat{i}_{0}^{Y^{*}}\right) d_{D}^{Y}}{\hat{p}_{D}^{*}} \\
& 1-\hat{i}_{0}^{T}=\hat{p}_{0}^{A D} \\
& \frac{\hat{i}_{0}^{Y}-\hat{i}_{D}^{Y}}{\hat{i}_{0}^{Y}-\hat{i}_{0}^{Y *}} \frac{\hat{p}_{D}^{*}}{\hat{p}_{D}-d_{D}^{Y} \hat{p}_{D}^{A D}}=1 \\
& \frac{\hat{i}_{D}^{Y}-\hat{i}_{0}^{Y^{*}}}{\hat{i}_{0}^{Y}-\hat{i}_{0}^{Y^{*}}}+\frac{\hat{i}_{0}^{Y^{*}}-\hat{i}_{D}^{Y^{*}}}{\hat{p}_{D}^{*}}\left(2+\hat{p}_{0}+\hat{p}_{0}^{*}\right)=1 \\
& \frac{\hat{i}_{D}^{T}}{\hat{i}_{0}^{T}} \hat{p}_{D}=d_{D}^{Y} \hat{p}_{D}^{A D} \\
& \frac{\hat{i}_{D}^{Y}}{\hat{p}_{D}-d_{D}^{Y} \hat{p}_{D}^{A D}}=\frac{\hat{i}_{D}^{Y}+\left(1-\hat{i}_{D}^{Y}\right) d_{D}^{Y}}{\hat{p}_{D}^{*}} \\
& \hat{p}_{D}^{*}=\hat{i}^{Y^{*}}+\left(1-\hat{i}^{Y^{*}}\right) d_{D}^{Y} \\
& 1-\hat{i}_{D}^{T}=\hat{p}_{D}^{A D} ;
\end{aligned}
$$




\section{Foreign Leverage and Home Tranching}

10 variables: $\hat{i}_{0}^{Y}, \hat{i}_{D}^{Y}, \hat{i}_{0}^{T}, \hat{i}_{D}^{T}, \hat{p}_{0}, \hat{p}_{0}^{*}, \hat{p}_{0}^{A D}, \hat{p}_{D}, \hat{p}_{D}^{*}, \hat{p}_{D}^{A D} .2$ Market clearing in 0,3 valuation in 0,2 market clearing in $\mathrm{D}, 3$ valuation in $\mathrm{D}$. With $\phi=\frac{1-d_{D}^{Y}}{2-d_{D}^{Y}}$.

$$
\begin{aligned}
& \left(1-\hat{i}_{0}^{Y}\right) \phi \frac{2+\hat{p}_{0}+\hat{p}_{0}^{*}}{\hat{p}_{0}-\hat{p}_{D} \hat{p}_{0}^{A D}}=1 \\
& \hat{i}_{0}^{T}\left(2+\hat{p}_{0}+\hat{p}_{0}^{*}\right)=\hat{p}_{D} \hat{p}_{0}^{A D} \\
& \frac{\hat{i}_{0}^{Y}}{\hat{p}_{0}-\hat{p}_{D} \hat{p}_{0}^{A D}}=\hat{i}_{0}^{Y}+\left(1-\hat{i}_{0}^{Y}\right) \frac{\hat{i}_{0}^{Y}}{\hat{p}_{D}-d_{D}^{Y} \hat{p}_{D}^{A D}} \\
& \frac{\hat{i}_{0}^{Y}}{\hat{p}_{0}-\hat{p}_{D} \hat{p}_{0}^{A D}}=\frac{\hat{i}_{0}^{Y}\left(1-\hat{p}_{D}^{*}\right)}{\hat{p}_{0}^{*}-\hat{p}_{D}^{*}} \\
& 1-\hat{i}_{0}^{T}=\hat{p}_{0}^{A D} \\
& \left(\hat{i}_{0}^{Y}-\hat{i}_{D}^{Y}\right) \phi \frac{2+\hat{p}_{0}+\hat{p}_{0}^{*}}{\hat{p}_{D}-d_{D}^{Y} \hat{p}_{D}^{A D}}=1 \\
& \frac{\hat{i}_{D}^{T}}{\hat{i}_{0}^{T}} \hat{p}_{D}=d_{D}^{Y} \hat{p}_{D}^{A D} \\
& \frac{\hat{i}_{D}^{Y}}{\hat{p}_{D}-d_{D}^{Y} \hat{p}_{D}^{A D}}=1 \\
& \frac{\hat{i}_{D}^{Y}}{\hat{p}_{D}-d_{D}^{Y} \hat{p}_{D}^{A D}}=\frac{\hat{i}_{D}^{Y}\left(1-d_{D}^{Y}\right)}{\hat{p}_{D}^{*}-d_{D}^{Y}} \\
& 1-\hat{i}_{D}^{T}=\hat{p}_{D}^{A D} ;
\end{aligned}
$$

